\title{
Surface modification of mineral dust particles by sulphuric acid processing: implications for ice nucleation abilities
}

\author{
P. Reitz ${ }^{1,2}$, C. Spindler ${ }^{3}$, T. F. Mentel ${ }^{3}$, L. Poulain ${ }^{4}$, H. Wex ${ }^{4}$, K. Mildenberger ${ }^{4}$, D. Niedermeier ${ }^{4}$, S. Hartmann ${ }^{4}$, \\ T. Clauss $^{4}$, F. Stratmann ${ }^{4}$, R. C. Sullivan ${ }^{5}$, P. J. DeMott ${ }^{5}$, M. D. Petters ${ }^{6}$, B. Sierau ${ }^{7}$, and J. Schneider ${ }^{1}$ \\ ${ }^{1}$ Particle Chemistry Department, Max Planck Institute for Chemistry, Mainz, Germany \\ ${ }^{2}$ Institute for Atmospheric Physics, Johannes Gutenberg University Mainz, Mainz, Germany \\ ${ }^{3}$ Institute for Energy- and Climate Research Troposphere (IEK-8), Research Center Jülich GmbH, Jülich, Germany \\ ${ }^{4}$ Department of Physics, Leibniz Institute for Tropospheric Research, Leipzig, Germany \\ ${ }^{5}$ Department of Atmospheric Science, Colorado State University, Fort Collins, USA \\ ${ }^{6}$ Department of Marine Earth and Atmospheric Science, North Carolina State University, Raleigh, USA \\ ${ }^{7}$ Institute for Atmospheric and Climate Science, ETH Zürich, Zürich, Switzerland
}

Received: 11 February 2011 - Published in Atmos. Chem. Phys. Discuss.: 2 March 2011

Revised: 20 July 2011 - Accepted: 21 July 2011 - Published: 3 August 2011

\begin{abstract}
The ability of coated mineral dust particles to act as ice nuclei (IN) was investigated at LACIS (Leipzig Aerosol Cloud Interaction Simulator) during the FROST1and FROST2-campaigns (Freezing of dust). Sulphuric acid was condensed on the particles which afterwards were optionally humidified, treated with ammonia vapour and/or heat. By means of aerosol mass spectrometry we found evidence that processing of mineral dust particles with sulphuric acid leads to surface modifications of the particles. These surface modifications are most likely responsible for the observed reduction of the IN activation of the particles. The observed particle mass spectra suggest that different treatments lead to different chemical reactions on the particle surface. Possible chemical reaction pathways and products are suggested and the implications on the IN efficiency of the treated dust particles are discussed.
\end{abstract}

\section{Introduction}

Aerosol particles have various direct and indirect effects on earth climate (Lohmann and Feichter, 2005). One of the important indirect effects is their ability to act as heterogeneous ice nuclei. Heterogeneous ice nucleation influences the earth radiation budget by the change of cloud albedo (Kay et al.,

Correspondence to: P. Reitz (p.reitz@mpic.de)
2007) and plays a major role in the formation of precipitation, especially in mid latitudes (Roedel, 2000). The exact effect of ice clouds on the Earth's climate is yet not well understood (Forster et al., 2007) and more research is needed to determine the mechanisms of heterogeneous ice nucleation (Cantrell and Heymsfield, 2005). Mineral dust has been found to be one of the major components of snow crystal residuals (Kamphus et al., 2010; Mertes et al., 2007; Richardson et al., 2007; Cziczo et al., 2004; DeMott et al., 2003). In the atmosphere mineral dust is often internally mixed with organic and inorganic material due to particle ageing processes in the atmosphere (Wiacek and Peter, 2009; Sullivan et al., 2007; Sullivan and Prather, 2007; Hinz et al., 2005; Falkovich et al., 2001). Such additions may influence the efficiency of mineral dust to act as ice nuclei (Sullivan et al., 2010a,b; Niedermeier et al., 2010; Gallavardin et al., 2008; Möhler et al., 2005, 2008). Niedermeier et al. (2010) found that active sites were lost when particles were processed with concentrated sulphuric acid and Sullivan et al. (2010b) show that the loss of these active sites was irreversible. However, the surface processes that lead to the destruction of active sites are not fully understood. Here we present a study of reactions taking place on the particle surface of Arizona Test Dust after processing with sulphuric acid. The experiments were performed during the FROST1 and FROST2 (Freezing of dust 1 and 2) campaigns at the LACIS (Leipzig Aerosol Cloud Interaction Simulator, (Hartmann et al., 2011; Stratmann et al., 2004)) facility located at the Institute for

Published by Copernicus Publications on behalf of the European Geosciences Union. 
Tropospheric Research in Leipzig, Germany. A unique combination of data from ice nucleus counters, a cloud condensation nucleus counter, and from aerosol mass spectrometers permitted deeper insights into the chemical processes taking place on the particle surface after processing with sulphuric acid. After condensing sulphuric acid on the particles, they were optionally humidified, chemically neutralised and heated. These treatments and the resulting aerosol properties modifications provided additional information on the nature of the processes taking place on the aerosol particle surfaces. The possibility to link surface modifications to the modification of freezing behaviour is valuable for attaining better understanding of the key characteristics that are responsible for the ability of mineral dust particles to act as ice nuclei.

\section{Methods}

\subsection{Particle generation}

Arizona test dust (ATD) (ISO 12103-1, A1 Ultrafine Test Dust, Powder Technology Inc., Burnsville, Minnesota, USA) was chosen as test substrate. Additional measurements were performed using quartz particles (BCR-66, European commission, Institute for Reference Materials and Measurements). A schematic of the set-up is shown in Fig. 1. It can be separated in two major blocks, the particle generation, shown on the left side of Fig. 1 and the particle characterisation, shown on the right side of Fig. 1. First, the ATD was dispersed in a fluidized bed generator (TSI 3400A, TSI Inc., St. Paul, Minnesota, USA). To generate aerosol with particles in the size range of 200 to $400 \mathrm{~nm}$ mobility diameter, ultra fine ATD was introduced into the disperser followed by a multi stage impactor with a $50 \%$ aerodynamic cut-off diameter at $560 \mathrm{~nm}$ (which corresponds to mobility diameter of approximately $450 \mathrm{~nm}$ ) placed immediately after the fluidized bed, to remove most of the big particles prior to any processing. For those experiments with $400 \mathrm{~nm}$ mobility diameter ATD, the impactor cut-off was increased to $1 \mu \mathrm{m}$ corresponding to a mobility diameter of approximately $800 \mathrm{~nm}$. The final selection of the aerosol diameter is performed at the end of the particle generation section using a DMA to select 200, 300 and $400 \mathrm{~nm}$ particles, respectively. By passing the aerosol over a heated sulphuric acid bath, controlled amounts of sulphuric acid were condensed on the particle surface, depending on the temperature of the bath. More details can be found in Niedermeier et al. (2010).

Additional processing by humidification of the aerosol was accomplished using a water bath downstream of the sulphuric acid bath. We have indirect evidence that an unknown amount of ammonia was present in the compressed air and/or the water bath section. We were not able to quantify this contamination. It should be noted that initial experiments showed that the uptake of ammonia to the particles without humidification is very slow. Accordingly only a very

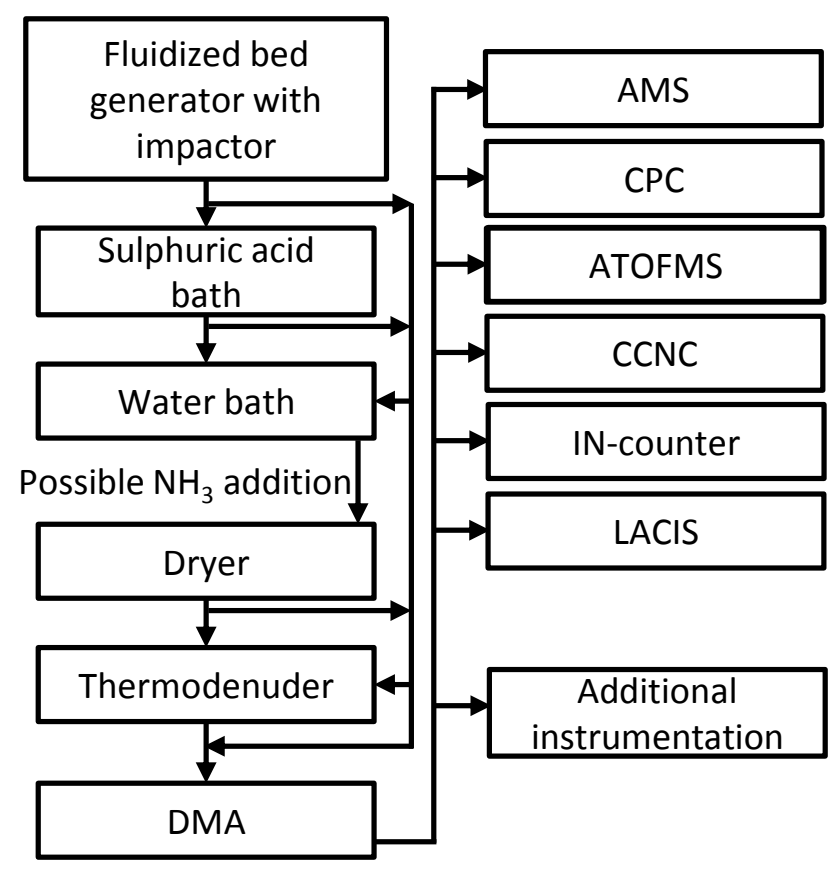

Fig. 1. Experimental set-up of the FROST campaigns. The sections between the Fluidized bed generator and the DMA can be bypassed.

weak neutralisation could take place without the water bath in line. For some experiments extra ammonia was added to the aerosol in order to ensure complete neutralisation. After the water bath and the ammonia section, the aerosol was dried again in a diffusion dryer. Finally a thermodenuder was available in order to remove the semi-volatile fraction of the particles. Unavoidably, the thermodenuder, which was set most of the time to $250^{\circ} \mathrm{C}$, also provoked a thermal treatment of the aerosol in a way that surface reaction kinetics and equilibria might have been changed. At the end of the particle generation a differential mobility analyser (DMA) was used to select a monodisperse fraction of the aerosol of $200 \mathrm{~nm}$, $300 \mathrm{~nm}$ or $400 \mathrm{~nm}$ mobility diameter. Doubly charged particle artefacts were mostly avoided as this size fraction had already previously been removed by the impactor. As the $300 \mathrm{~nm}$ particles yielded the highest number concentration without doubly charged particles, they were used for most of the studies. Except for the DMA, all processing following the dispersion of the dust was optional and could be bypassed.

\subsection{Particle characterisation}

The aerosol was characterised with respect to concentration, morphology, hygroscopic growth, CCN activity, IN activity and chemical composition. In this paper we will focus on the results from the chemical analysis performed by an aerosol mass spectrometer (AMS) (Jayne et al., 2000; Drewnick et al., 2005) and compare the results to the CCN and IN activity measured by a cloud condensation nucleus 
counter (CCNC, Roberts and Nenes, 2005), an ice nucleus counter (CFDC, Sullivan et al., 2010b, original instrument version: Rogers et al. (2001)) and the Leipzig Aerosol Cloud Interaction Simulator LACIS (Hartmann et al., 2011; Stratmann et al., 2004), which measured both $\mathrm{CCN}$ and IN efficiency. However, this study focuses on the IN data measured with LACIS. Data from an Aerosol Time of Flight Mass Spectrometer (ATOFMS) (Nordmeyer and Prather, 1994) was used to estimate the number-fraction of particles coated.

\subsubsection{Determination of the particle soluble mass loadings from $\mathrm{CCNC}$ data}

A detailed discussion of the hygroscopic growth properties of the probed aerosol is given in Wex et al. (2011). In the CCNC the supersaturation was varied in the range of 0.07 to $0.6 \%$ supersaturation and the number concentration fraction of activated particles was recorded. The supersaturation at which $50 \%$ of the particles were activated as cloud droplets was considered to be the critical supersaturation. As the aerosol is nearly monodisperse, the curves obtained show a relatively steep increase at a given supersaturation. To facilitate comparisons between AMS data and CCNC data, soluble mass loadings per particle have been calculated using single parameter Köhler theory (Petters and Kreidenweis, 2007; Wex et al., 2007). At the supersaturation $S_{\text {crit }}$ at which the particles activate, the maximum of the Köhler curve was calculated to determine the apparent hygroscopicity parameter $\kappa_{\text {app }}$ which can then be compared to $\kappa_{\text {coat }}$ of the pure substance used as the coating material. Equation (1) shows the Köhler equation linking the wet size $D$ of a particle to the saturation ratio $S$ needed.

$$
S(D)=\frac{D^{3}-D_{\mathrm{dry}}^{3}}{D^{3}-D_{\mathrm{dry}}^{3}\left(1-\kappa_{\mathrm{app}}\right)} \exp \frac{A}{D}
$$

$D_{\text {dry }}$ is the dry diameter of the particle and $A$ is a constant that depends on the temperature and the surface tension at the solute/air interface. We use the term "apparent" hygroscopicity, as we determine the intrinsic hygroscopicity, biased by the possibly limited solubility of a fraction of the particle material (Sullivan et al., 2009b; Petters and Kreidenweis, 2008). The apparent hygroscopicity is the additive value of the apparent hygroscopicities of individual components of the particle weighted by their volume fractions. With $\kappa_{\text {coat }}$ being the hygroscopicity parameter of the coating substance, $\kappa_{\mathrm{ATD}}$ being the hygroscopicity parameter of the unprocessed ATD and $\epsilon_{\text {coat }}$ and $\epsilon_{\mathrm{ATD}}$ their respective volume fractions, we get Eq. (2) for $\kappa_{\text {app }}$ :

$$
\kappa_{\mathrm{app}}=\epsilon_{\mathrm{coat}} \kappa_{\mathrm{coat}}+\epsilon_{\mathrm{ATD}} \kappa_{\mathrm{ATD}}
$$

As the sum of the volume fractions must be equal to 1 $\left(\epsilon_{\text {coat }}+\epsilon_{\mathrm{ATD}}=1\right)$, Eq. (2) can be rearranged to get the volume fraction of the coating (Sullivan et al., 2009a). This volume fraction can be multiplied by the particle volume and the density of the coating material, yielding the mass of the soluble fraction of the particle (Eq. 3). $\kappa_{\text {app }}$ of the ATD was found to be 0.002 (Sullivan et al., 2010b).

$$
\begin{aligned}
m_{\text {soluble }} & =\rho_{\text {soluble }} \times V_{\text {coat }} \\
& =\rho_{\text {soluble }} \times V_{\text {total }} \times \epsilon_{\text {coat }} \\
& =\rho_{\text {soluble }} \times V_{\text {total }} \times \frac{\kappa_{\text {app }}-\kappa_{\text {ATD }}}{\kappa_{\text {coat }}-\kappa_{\text {ATD }}}
\end{aligned}
$$

This method works best if no reactions take place on the particle surface, as these can result in the formation of unknown substances for which the hygroscopicity parameter and the density are no longer exactly known.

\subsubsection{Determination of IN efficiency}

The CFDC is a continuous flow diffusion chamber. The dry aerosol enters a region between two cylinders which are coated with ice and set to a controlled temperature. By creating a temperature gradient between the cylinder walls, the saturation ratio between the walls can be controlled. Particles which activate and grow to ice crystals are counted with an optical particle counter at the end of the chamber. The instrument can measure both in immersion/condensation freezing mode (particles activate as cloud droplets before freezing) as well as in deposition freezing mode (water vapour directly deposits on the particles to form ice without prior activation of the particles as liquid droplets). The different freezing modes are described in Pruppacher and Klett (1997). Details about the CFDC chamber used during the FROST2 campaign are described in Sullivan et al. (2010b).

In the LACIS chamber, moisture conditioned aerosol is cooled down in a laminar flow tube in order to achieve supersaturation above water. The supersaturation and the temperature of the aerosol are controlled via the wall temperatures and the initial air moisture. Downstream of the activation of the particles to droplets, further cooling occurs, that can eventually lead to the freezing of the droplets. At the outlet an optical particle counter is used to detect the ice and the droplets formed. Ice is formed in the immersion freezing mode. Details about the LACIS chamber and its use as an ice nucleation instrument are given in Hartmann et al. (2011). Both CFDC and LACIS data are shown in Figs. 10 and 11, respectively.

\subsubsection{Determination of the chemical composition of the particles' non refractory fraction}

In the AMS particles of $40 \mathrm{~nm}$ to $1000 \mathrm{~nm}$ vacuum aerodynamic diameter are focused on a narrow particle beam using an aerodynamic lens. $100 \%$ transmission is achieved for particles in the range from $60 \mathrm{~nm}$ to $600 \mathrm{~nm}$ vacuum aerodynamic diameter (Liu et al., 2007). The focused particle beam is introduced into a differentially pumped vacuum chamber and directed onto a thermal vaporiser whose temperature was 
set to $600{ }^{\circ} \mathrm{C}$ or $820^{\circ} \mathrm{C}$. The use of two different evaporation temperatures provided additional information on the volatility of the particle material, allowing further restriction of its possible composition. The produced vapour is ionized by $70 \mathrm{eV}$ electron impaction and the positive ion fraction is focused into an orthogonal extraction time-of-flight mass spectrometer.

The main objective of the AMS measurements was to quantify the amount of sulphuric acid condensed on the particle surface. The temperatures set at the AMS vaporiser are far too low to evaporate mineral dust like ATD (melting point according to manufacturer: $1615 \pm 75^{\circ} \mathrm{C}$ ). Rather, the instrument is sensitive to the more volatile fraction of the particles, thereby enabling the detection of even very low amounts of non-refractory material on the refractory particle cores. As the aerosol was quasi monodisperse, the average mass per particle could be calculated by normalising the mass concentrations given by the AMS to the particle number concentration from a condensation particle counter (CPC) that was operated parallel to the AMS.

To accurately quantify the mass per particle of the sulphuric acid and its chemical reaction products, the AMS mass concentrations must be corrected for systematic errors. These include deviations of the relative ionisation efficiency (RIE) from the standard values and the collection efficiency (CE) of the instrument for ATD like particles. The particle size range used in this study exceeded $600 \mathrm{~nm}$ in vacuum aerodynamic diameter, which is the maximum particle size which is transmitted without losses into the instrument. The amount of particles lost in the instrument inlet has been calculated and the data was corrected for these losses. Details about the calculation of the correction factors are presented in the appendix (Sect. A).

In addition to the AMS, an Aerosol Time of Flight Mass Spectrometer (ATOFMS; TSI Model 3800) was used in this study to determine aerodynamic size and chemical composition of single particles. It uses an aerodynamic sizing technique to measure particle size and time of flight mass spectrometry to determine the chemical composition of particles of unit mass resolution. Particles in the size range between approximately $200-3000 \mathrm{~nm}$ are drawn into the instrument through a nozzle inlet and are first aerodynamically sized by measuring their transit time in between two laser beams of known distance. Downstream of the sizing region, the particles reach the ion source region where the particles are hit by pulsed UV laser fires that induces laser desorption/ionisation. Due to the bipolar design of the mass spectrometer, a positive and a negative ion spectrum are acquired from each particle.

The main differences compared to the AMS are the capability of the ATOFMS to analyse single particles, as well as to collect information on refractory materials such as sodium chloride, elemental carbon and mineral dust constituents due to the different ionisation method applied. However, compared to the AMS, the ATOFMS does not measure mass concentrations. A common method to analyse ATOFMS spectra is to classify analysed particles into groups of certain mass spectrometric signatures (e.g.: Kamphus et al., 2010) which was also done in the context of this experiment. Particles showing a peak at $m / z=-97\left(\mathrm{HSO}_{4}^{-}\right)$in the mass spectra were identified as sulphates. Applying different peak thresholds (conservative: peak area $>1000$ a.u.; less conservative: peak height $>50$ a.u.), the number fraction of particles that produce a sulphate ion signal could be determined.

\section{Results and discussion}

The presentation of the results starts with the identification of chemical compounds found in the non-refractory fraction of the ATD followed by the quantification of the average mass per particle for the main species. We show evidence for reactions of the sulphuric acid with the particle surface and propose possible products for these reactions depending on the applied treatments. The mass per particle loadings, as deduced from the AMS data, are compared to the soluble mass fractions calculated from the CCNC activation curves. This comparison allows for further restricting the possible products on the particles' surface. Finally, the effects of the different treatments are linked to the IN-fractions determined by the CFDC and LACIS, to show their effects on the IN-ability of ATD.

In general, for all particles the mass per particle was calculated for the species organics, sulphate, ammonium and silicone. The species chloride and nitrate were always below the AMS detection limits. The detection limits have been calculated from the amplitude of the noise of the background signal similar as in Drewnick et al. (2009) using an algorithm described in Reitz and Schneider (2011) to separate long scale background fluctuations from statistic noise. The correction factors described in Sect. 2 were applied to all species.

\subsection{Average non-refractory mass per particle}

The average non-refractory mass per particle was determined by normalising the mass concentrations of carbon containing material (CCM), sulphate, ammonium and silicone measured with the AMS to the particle number concentration measured by a CPC. The term CCM was introduced instead of the term organics, as it also contains carbonates and methyl silicone, which cannot be clearly distinguished from organic material. The fragmentation table is the same as for organics (Allan et al., 2004). The ATOFMS data show that, depending on the respective signal area threshold used, 84 to $97 \%$ or 93 to $100 \%$ of the particles contained sulphate after passing the sulphuric acid coating section. Based on the signal quality of the individual mass spectra, the less conservative threshold can be applied for the investigated experiments. However, sulphate peaks were also detected for "pure" ATD particles, which makes the identification of sulphate compounds 


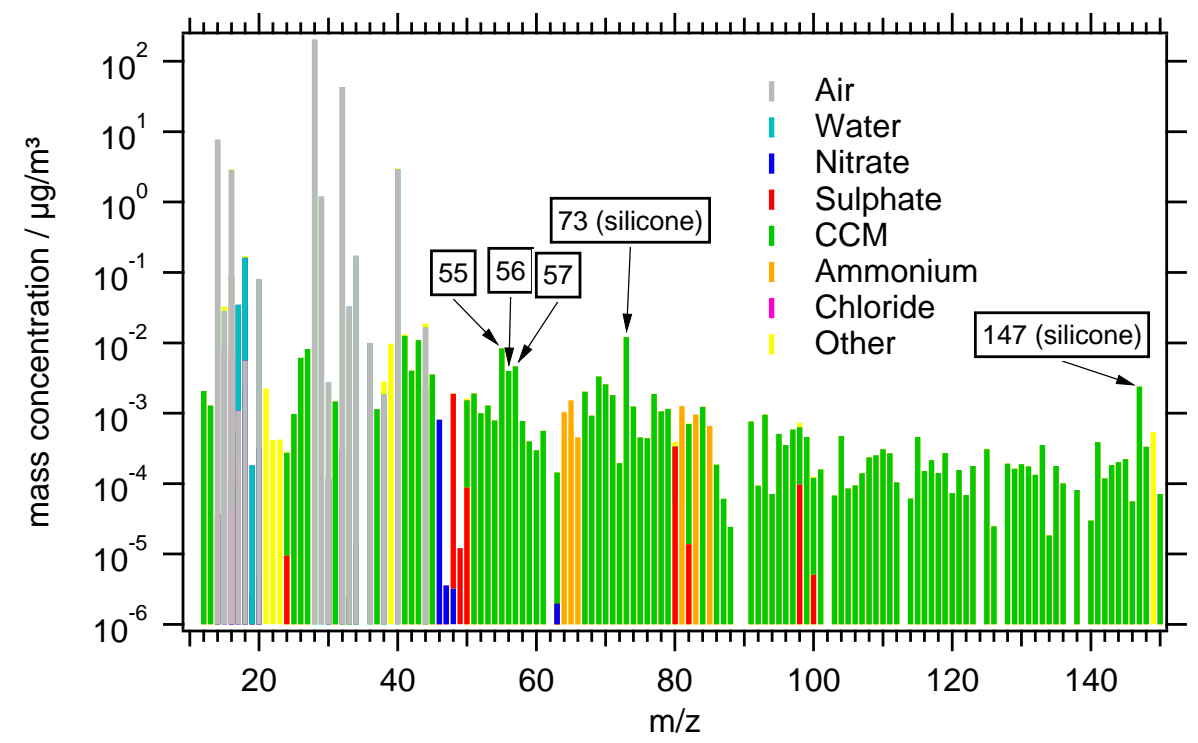

Fig. 2a. Average AMS mass spectrum for unprocessed ATD during the FROST1 campaign. The AMS vaporiser was set to $600^{\circ} \mathrm{C}$. Notable are the clear peaks that can be attributed to methyl silicone contaminant.

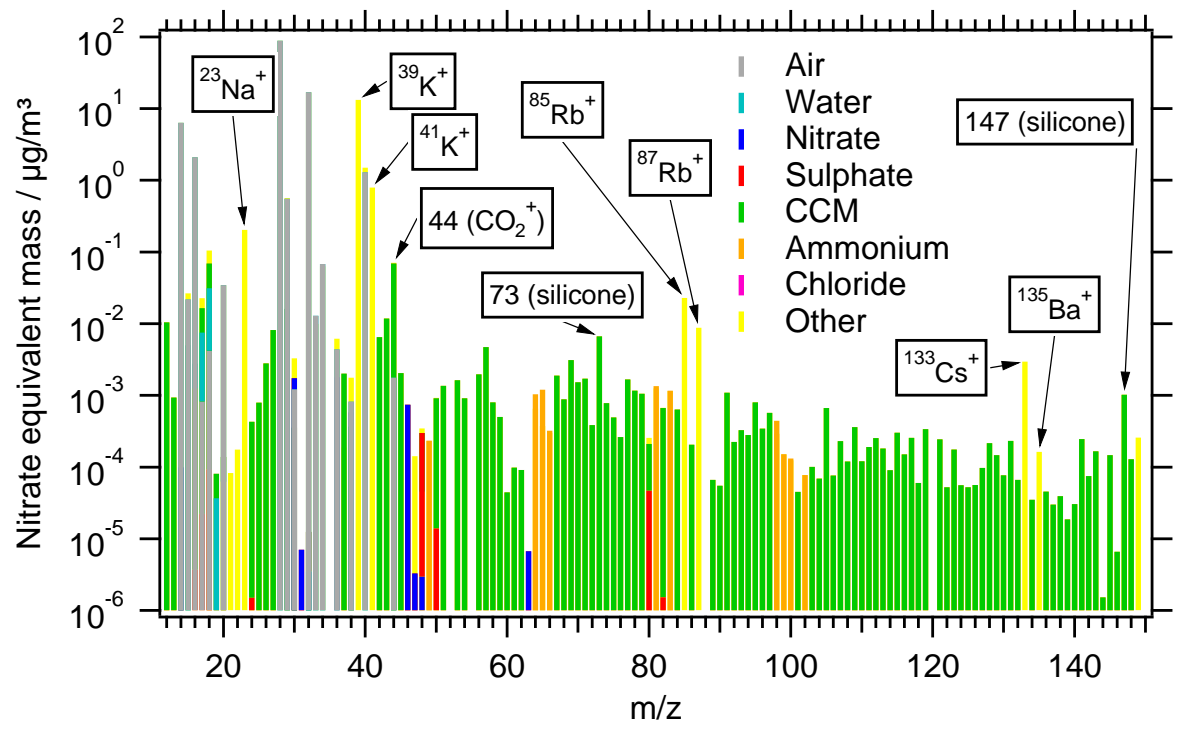

Fig. 2b. Average AMS mass spectrum for untreated ATD during the FROST2 campaign. Beside the silicone peaks already visible during FROST1, some new very distinct metal peaks show up in this spectrum, due to the elevated vaporiser temperature of $820^{\circ} \mathrm{C}^{23} \mathrm{Na}^{+},{ }^{39} \mathrm{~K}^{+}$, ${ }^{41} \mathrm{~K}^{+},{ }^{85} \mathrm{Rb}^{+},{ }^{87} \mathrm{Rb}^{+},{ }^{133} \mathrm{Cs}^{+}$and ${ }^{135} \mathrm{Ba}^{+}$.

on the particles somewhat ambiguous. The fraction of pure ATD particles that showed a sulphate peak ranges from 3 to $8 \%$ and 5 to $46 \%$ using similar threshold definitions as described above. The fact that a small fraction of the coated particles showed no sulphate peak in the ATOFMS is likely related to the very low amounts of sulphate on the particle surface. Due to this it is possible that even when sulphate was present, it did not necessarily produce a significant signal in the ATOFMS. The CCNC data also indicated that the aerosol was not externally mixed, as the activation of the particles took place in a small supersaturation interval without showing multiple steps. This would have been expected in case of an uncoated fraction (Wex et al., 2011). A compilation of the coated particle fraction determined with the ATOFMS is shown in Table 1.

Figure $2 \mathrm{a}$ to $2 \mathrm{c}$ show average mass spectra recorded during the FROST1 and FROST2 campaign for particles of $200 \mathrm{~nm}$ and $300 \mathrm{~nm}$, respectively. No correction factors have been applied for these graphs. Figure 2a shows the data measured using ATD without sulphuric acid processing. Two clear 


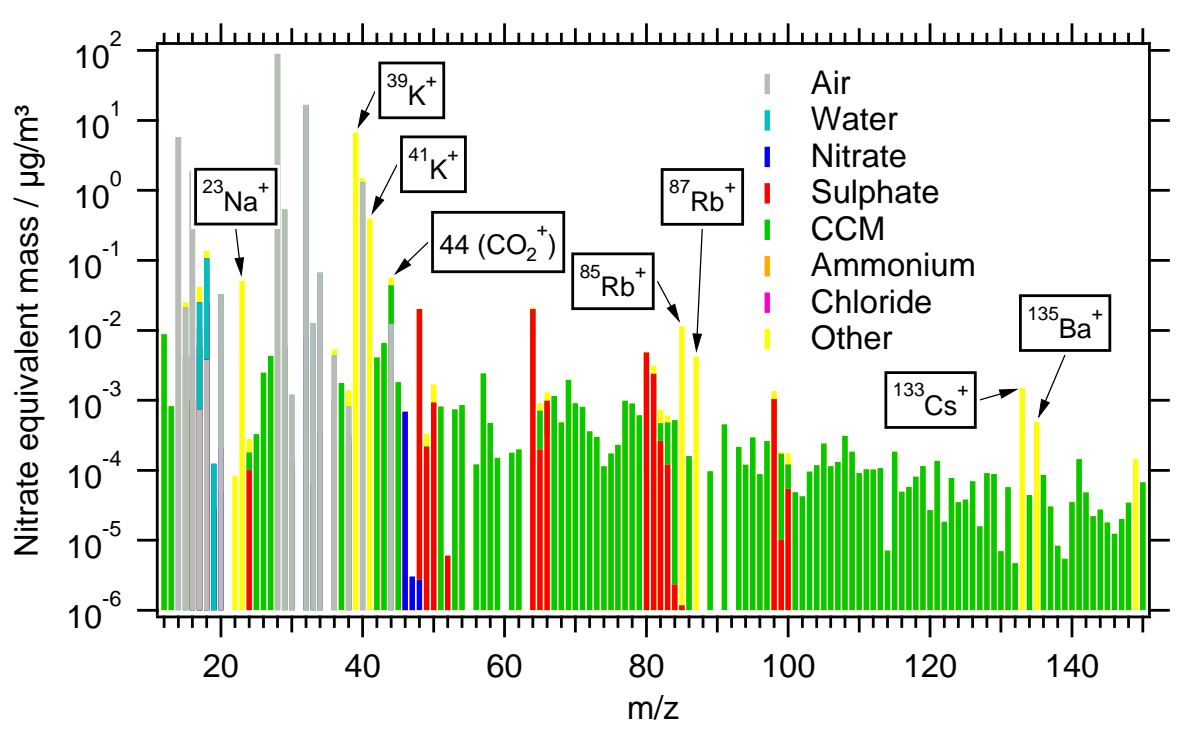

Fig. 2c. Average AMS mass spectrum of sulphuric acid processed ATD during the FROST2 campaign. The sulphuric acid bath temperature was $70^{\circ} \mathrm{C}$. Beside the sulphate peaks in red, the metal peaks that were already visible in the unprocessed $820^{\circ} \mathrm{C}$ data remain visible. The silicone probably reacted with the sulphuric acid and is no longer visible.

methyl silicone peaks are visible. The silicone probabely originated from the compressed air the ATD was suspended in. It was not detected for those experiments where sulphuric acid was still present on the particle surface when entering the AMS. This indicates that the sulphuric acid reacted with silicone on the surface and prevented new silicone from condensing. If the sulphuric acid reacted during the aerosol preparation and was consumed, silicone was again detected. It is therefore expected that the silicone at least partialy condensed on the particles' surfaces afer the size selection with the DMA. In addition, organic material is visible, especially on the mass to charge ratios $(\mathrm{m} / \mathrm{z}) 55,56$ and 57 which are clearly organic markers. Figure $2 b$ shows pure ATD from the FROST2 campaign, during which the vaporiser temperature was increased by $220^{\circ} \mathrm{C}$ compared to FROST1. The higher temperature leads to a stronger decomposition of the oxygenated organics and to the decomposition of carbonates (see extensive study by Zhao et al., 2010), resulting in a rise of the $\mathrm{CO}_{2}^{+}$fragment. Only the $\mathrm{CO}_{2}$ released by the decomposition can be detected as the remaining metal oxides are refractory at the temperature of $820^{\circ} \mathrm{C}$. For example $\mathrm{CaO}$ melts at temperatures above $2500{ }^{\circ} \mathrm{C}$. From the three organic markers at $m / z=55,56$, and 57 detected during FROST1, only the signal on $m / z 57$ is still visible in the FROST 2 experiments with the higher vaporizer temperature. A second effect of the high vaporiser temperature is the appearance of alkali metal peaks $\left(\mathrm{Na}^{+}, \mathrm{K}^{+}, \mathrm{Rb}^{+}\right.$and $\left.\mathrm{Cs}^{+}\right)$as well as $\mathrm{Ba}^{+}$, the stable alkaline earth metal with the lowest electronegativity. These peaks only appear when ATD is introduced into the instrument and are missing during e.g. calibration measurements with ammonium nitrate. It is possible that a low amount of alkali metals from the ATD were surface ionised (Svane et al., 2004, 2005). Given their very low electronegativity they are extremely easily ionised and low amounts would already produce high signals. The analysis of ATD in Vlasenko et al. (2005) did only show $\mathrm{Na}^{+}$and $\mathrm{K}^{+}$of these metals, but others might have been below the detection limit of the X-ray photo-electron spectrometer used for this analysis or were not included at all. The silicone signal which was identified in FROST1 is also present in the FROST2 data and the quartz particle (BCR-66, see Sect. A2) measurements. Figure $2 \mathrm{c}$ originates from a FROST2 measurement with sulphuric acid bath temperature of $70^{\circ} \mathrm{C}$ with an average sulphate mass of $1.870 \times 10^{-12} \mu \mathrm{g}$ particle ${ }^{-1}$. The resulting sulphate peaks are marked in red. The silicone peaks are no longer visible in this data. We suppose that they were oxidised by the sulphuric acid. The metal peaks remain, as expected for the vaporiser temperature of $820^{\circ} \mathrm{C}$.

In Fig. 3, the non-refractory mass per particle for uncoated and coated particles measured during the FROST1 campaign is shown. In FROST1, the vaporiser of the AMS was set to $600{ }^{\circ} \mathrm{C}$. At this temperature we expect sulphuric acid, ammonium sulphate, organic compounds as well as silicone to evaporate. Carbonates, however, do not decompose efficiently. The left graph of Fig. 3 shows that on uncoated ATD particles, the detected silicone and carbon containing matter (CCM) in mass per particle is approximately proportional to the square of the particle diameter and thus to the particle surface area. This implies that these substances are most likely surface contaminants of the ATD particles. On particles coated with sulphuric acid, the coating mass per particle increases with the square of the particle diameter 
Table 1. Compilation of the percentage of particles showing a clear sulphate signal in the ATOFMS spectra after passing the sulphuric acid coating section. The temperature indicated is the temperature of the sulphuric acid coating bath. TD indicates the use of the thermodenuder which, if applied, was set to $250^{\circ} \mathrm{C}$ for all experiments. WB marks experiments with the water bath in use and $\mathrm{NH}_{3}$ refers to experiments during which ammonia was added to the aerosol.

\begin{tabular}{|c|c|c|c|c|c|c|}
\hline Experiment & $45^{\circ} \mathrm{C}$ & $70^{\circ} \mathrm{C}$ & $\begin{array}{c}70^{\circ} \mathrm{C} \\
\mathrm{TD}\end{array}$ & $\begin{array}{c}70^{\circ} \mathrm{C} \\
\mathrm{WB} \\
\mathrm{NH}_{3}\end{array}$ & $\begin{array}{c}70^{\circ} \mathrm{C} \\
\mathrm{WB} \\
\mathrm{NH}_{3} \\
\mathrm{TD}\end{array}$ & $85^{\circ} \mathrm{C}$ \\
\hline Conservative threshold [\%] & 97 & 92 & 96 & 84 & 93 & 89 \\
\hline Less conservative threshold [\%] & 100 & 95 & 100 & 93 & 95 & 94 \\
\hline
\end{tabular}

(Fig. 3, right graph) when the sulphuric acid bath is operated at $70^{\circ} \mathrm{C}$. For particles which were coated at a temperature of $50^{\circ} \mathrm{C}$ the increase in sulphate is lower than the increase in surface area. It is possible that at lower $\mathrm{H}_{2} \mathrm{SO}_{4}$ bath temperatures $\left(50^{\circ} \mathrm{C}\right)$ insufficient $\mathrm{H}_{2} \mathrm{SO}_{4}$ is released to the gas phase to coat larger particles with the same thickness as smaller particles. However, for the later evaluation this is not relevant.

Figure 4 shows the measured mass per particle values for $300 \mathrm{~nm}$ particles as a function of the coating bath temperature. The left graph of Fig. 4 shows the amount of coating material as a function of the coating bath temperature. As expected we find an increase of sulphate with increasing bath temperature. This increase is larger for $820^{\circ} \mathrm{C}$ vaporiser temperature than for $600{ }^{\circ} \mathrm{C}$, indicating that a certain amount of sulphate is not evaporated at $600^{\circ} \mathrm{C}$. Experiments with the thermodenuder in operation at $250^{\circ} \mathrm{C}$ also indicate that a certain amount of the sulphate coating is not evaporated at $250^{\circ} \mathrm{C}$.

Average coating thicknesses could be estimated assuming that the surface area of the ATD particles was equal to the surface area of a sphere with the same mobility diameter than the ATD particles. The coating thickness was estimated to $1.8 \mathrm{~nm}$ for the lowest coating temperature of $45^{\circ} \mathrm{C}$ when sulphuric acid was condensed on the particle surface without further processing. For the highest temperature a coating thickness of $7 \mathrm{~nm}$ was estimated.

The right graph in Fig. 4 shows that CCM and silicone decreased with increasing bath temperature, as both species potentially react with sulphuric acid. Also for the $200 \mathrm{~nm}$ particles (not shown), the silicone signal is reduced to zero for $70^{\circ} \mathrm{C}$ coating temperature and also shows a reduction at 45 and $50^{\circ} \mathrm{C}$. In contrast, $\mathrm{CCM}$ is not reduced at higher $\mathrm{H}_{2} \mathrm{SO}_{4}$ bath temperatures (Fig. 4, right graph).

To study the influence of humidity and neutralisation by ammonia, particles were humidified after the coating and afterwards optionally exposed to an elevated ammonia gas concentration. The left graph of Fig. 5 shows the sulphate mass per particle for these experiments with $300 \mathrm{~nm}$ particles for vaporiser temperatures of $600^{\circ} \mathrm{C}$ and $820^{\circ} \mathrm{C}$.
Interestingly, the sulphate signal is clearly reduced after this processing for the lower vaporiser temperature, while it is increased for higher vaporiser temperatures. This indicates a reaction of $\mathrm{H}_{2} \mathrm{SO}_{4}$ with some particle components, forming a reaction product that cannot be evaporated by the AMS at $600^{\circ} \mathrm{C}$ but at $820^{\circ} \mathrm{C}$. Further indication for such a reaction is the finding that silicon is not removed as effectively during these experiments than it is during the experiments without humidification. Thus, humidification appears to accelerate the reaction of $\mathrm{H}_{2} \mathrm{SO}_{4}$ with the surface components of the particle.

The right graph of Fig. 5 shows the data for $820^{\circ} \mathrm{C}$ vaporiser temperature and data where the thermodenuder was additionally applied at $250{ }^{\circ} \mathrm{C}$. There is a reduction of the sulphate signal by 10 to $20 \%$ for both data sets (with and without $\mathrm{NH}_{3}$ ), but the decrease of the sulphate signal is by far smaller than in Fig. 4 (right graph) where the pure $\mathrm{H}_{2} \mathrm{SO}_{4}$ coating was treated by the thermodenuder. This is a further indication for the accelerated reaction by humidifying the coated particles, leading to the formation of a low-volatility product.

The addition of ammonia to the aerosol has no clear effect to any of the experiments. Nevertheless, for those experiments with the water bath in use, the amount of ammonium detected is increased. In the case of the experiments with a coating bath temperature of $85^{\circ} \mathrm{C}$, the experiments with water bath provided sufficient ammonia for neutralisation of about $50 \%$ of the sulphuric acid. These two experiments are the only experiments for which the ammonium signal was high enough to be detected. With the thermodenuder, the ammonium signal is reduced by approximately a factor of four but could not be quantified anymore.

\subsection{ATD surface reactions}

Analysing the effects of the thermodenuder and applying the water bath gave insight into the possible reactions taking place on the particle surface. For that we analysed the mass per particle and the fragmentation pattern. Figure 6 shows the expected fragmentation for sulphuric acid, ammonium sulphate and metal sulphate salts. Only sulphuric acid 

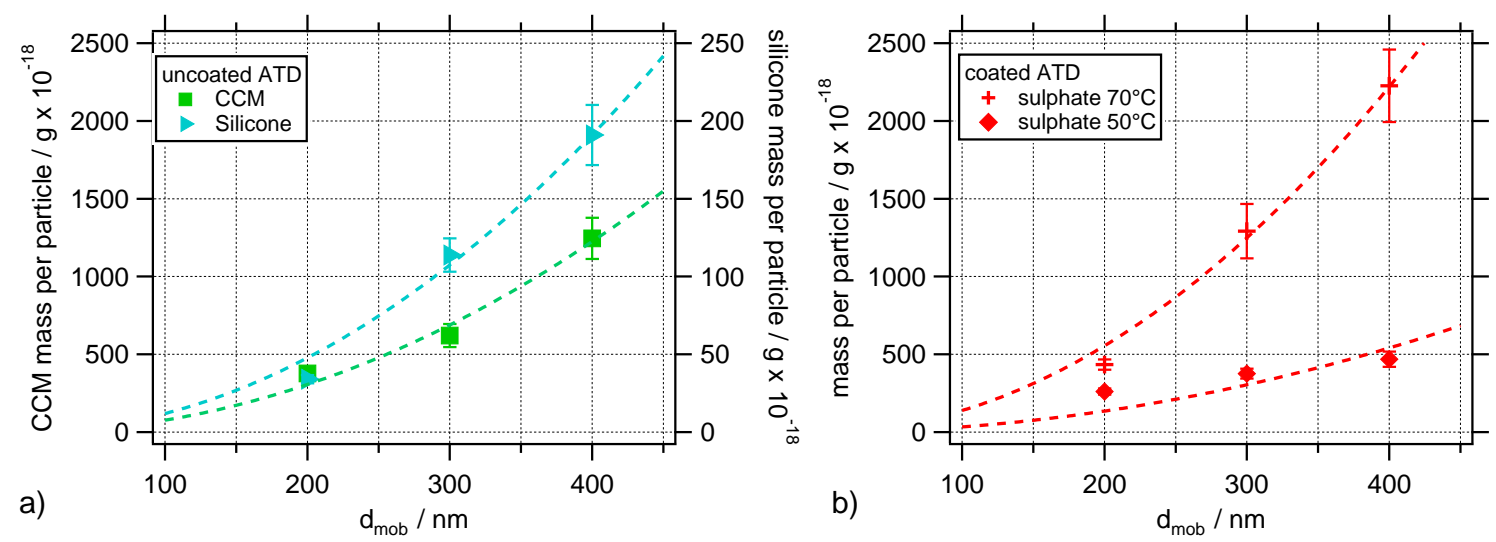

Fig. 3. Left: non-refractory mass per particle for uncoated ATD particles as a function of particle diameter. Vaporiser temperature: $600{ }^{\circ} \mathrm{C}$ (FROST1). The quadratic fits forced through zero indicate that both CCM (carbon-containing material, left scale) and silicone (right scale) are contaminants on the surface of the ATD particles. Right: sulphate coating $\left(50^{\circ} \mathrm{C}\right.$ and $70^{\circ} \mathrm{C}$ coating bath temperature) as a function of particle diameter. The quadratic fit forced through zero indicates that the coating mass per particle is proportional to the particle surface for a coating temperature of $70^{\circ} \mathrm{C}$.
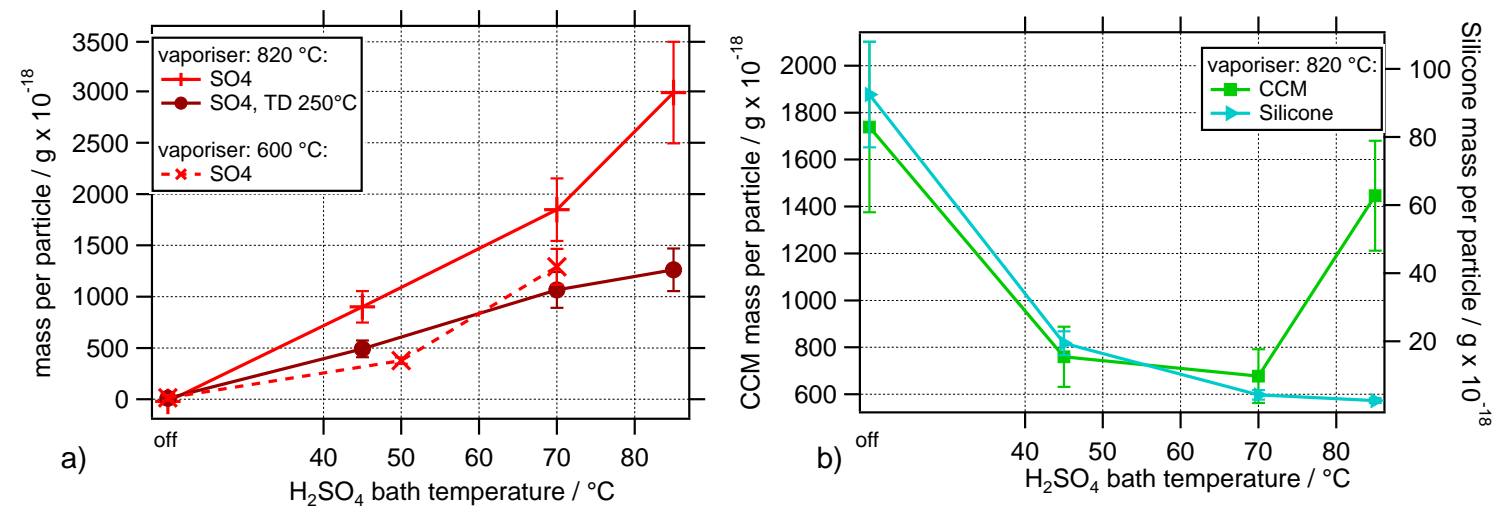

Fig. 4. Left: sulphate coating (mass per particle) as a function of the $\mathrm{H}_{2} \mathrm{SO}_{4}$ bath temperature, detected at $600^{\circ} \mathrm{C}$ and $820^{\circ} \mathrm{C}$ vaporiser temperature. The thermodenuder (TD) operated at $250^{\circ} \mathrm{C}$ removes only part of the sulphate. Right: silicone and carbon containing mass $(\mathrm{CCM})$ on $300 \mathrm{~nm}$ ATD particles coated with sulphuric acid. AMS vaporiser temperature: $820^{\circ} \mathrm{C}$ (FROST2). Silicone is efficiently destroyed by $\mathrm{H}_{2} \mathrm{SO}_{4}$ while a certain amount of CCM remains on the particle.

and ammonium sulphate can produce the hydrogen containing fragments $\mathrm{HSO}_{3}^{+}$and $\mathrm{H}_{2} \mathrm{SO}_{4}^{+}$, which cannot be formed from metal sulphate salts.

We suggest that the following reactions took place on the particle surface. The actual chemistry may be much more complex and part of the reactions shown below for one category will also take place in other categories. In order to improve readability, the reactions are only shown for a generic metal $\mathrm{M}$ with valency of 3 (e.g. $\mathrm{Al}$ or $\mathrm{Fe}(\mathrm{III})$ ) and assuming that the mineral includes carbonate. They can be easily rewritten with metals with a different valency (e.g.: K, $\mathrm{Ca}$ or $\mathrm{Fe}(\mathrm{II})$ ) or combinations of different metals and with different anions (e.g.: $\mathrm{OH}^{-}$or $\mathrm{PO}_{4}^{3-}$ or even $\mathrm{SiO}_{3}^{4-}$ ). The equations are not equilibrated as we do not know the relative quantities of the reaction products.
The first set of reactions refers to experiments during which the particles were treated with the water bath after the coating with sulphuric acid:

$$
\begin{array}{ll}
\stackrel{\mathrm{H}_{2} \mathrm{O}\left(\mathrm{CO}_{3}\right)_{3}+\mathrm{H}_{2} \mathrm{SO}_{4}+\mathrm{NH}_{3}}{\rightarrow} & \mathrm{M}_{2}\left(\mathrm{SO}_{4}\right)_{3}+\mathrm{MNH}_{4}\left(\mathrm{SO}_{4}\right)_{2}+\left(\mathrm{NH}_{4}\right)_{2} \mathrm{SO}_{4} \\
& +\mathrm{CO}_{2}(\mathrm{~g})+\mathrm{H}_{2} \mathrm{O}(\mathrm{g}) \\
\stackrel{\text { vaporiser }}{\rightarrow} & \mathrm{M}_{2} \mathrm{O}_{3}+\mathrm{NH}_{3}(\mathrm{~g})+\mathrm{SO}_{\mathrm{i}}(\mathrm{g}) \\
& +\mathrm{H}_{2} \mathrm{SO}_{4}(\mathrm{~g})+\mathrm{H}_{2} \mathrm{O}(\mathrm{g})
\end{array}
$$

After Reaction (R1), metal sulphates, mixed sulphates of metals and ammonium as well as ammonium sulphate were expected to form on the particle surface. Carbon dioxide was released to the gas phase and water evaporated when the particles were dried again after the water bath. Accordingly, both substances were not expected to be detected on 

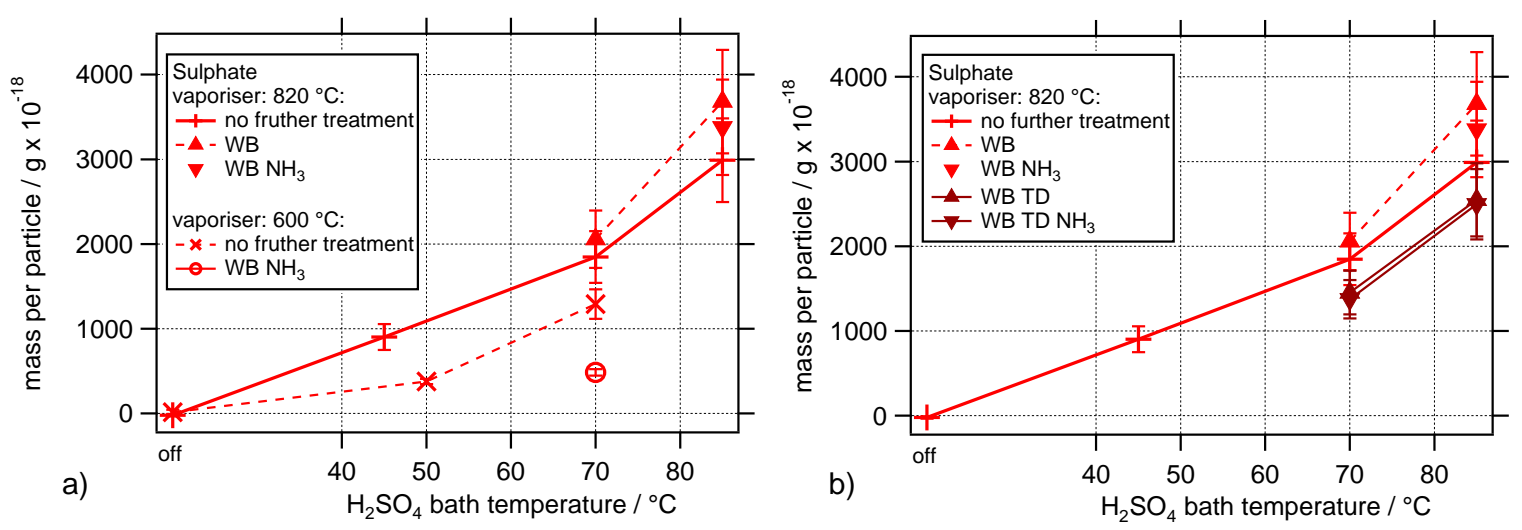

Fig. 5. Left: sulphate mass per particle for $\mathrm{H}_{2} \mathrm{SO}_{4}$ coatings with additional humidification (WB) and optional neutralisation by $\mathrm{NH}_{3}$ detected at vaporiser temperatures of $600^{\circ} \mathrm{C}$ and $820^{\circ} \mathrm{C}$. Right: sulphate mass per particle for the $820^{\circ} \mathrm{C}$ vaporiser data of the left graph, treated additionally by the thermodenuder (TD).

Sulphuric acid or ammonium sulphate

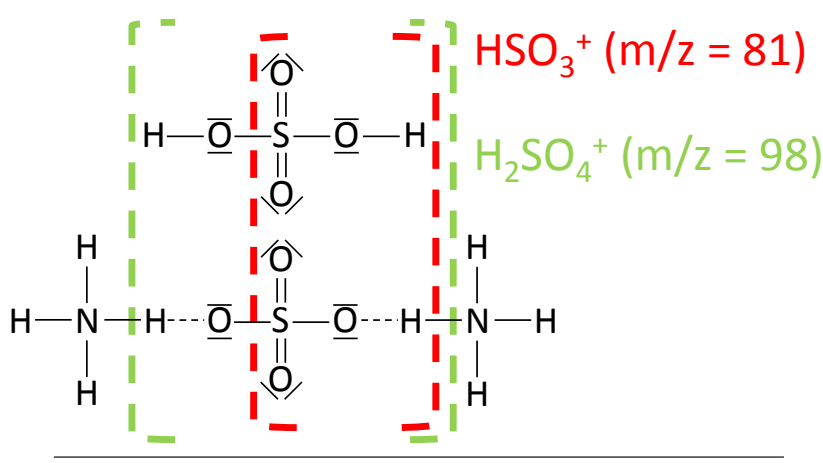

\section{Metal sulphate salt}

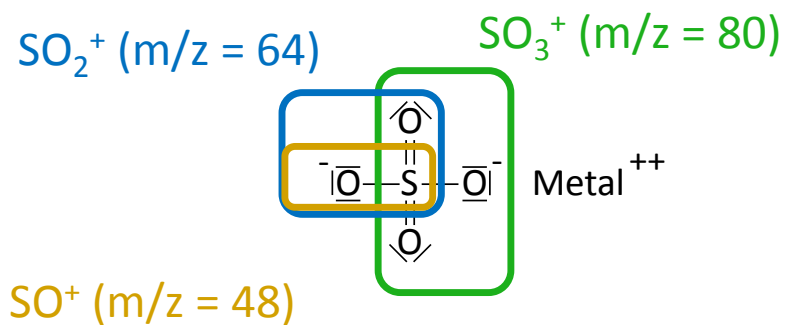

Fig. 6. Comparison between the possible fragments attributed to sulphate depending on the compound the sulphate is part of. For ammonium sulphate and sulphuric acid, hydrogen containing fragments are produced in the vaporisation and ionisation process while metal sulphate salts cannot produced such fragments.

the ATD surface. In the AMS, the heat of the vaporiser decomposed the metal sulphates into metal oxides and sulphur oxides $\left(\mathrm{SO}_{\mathrm{i}}\right)$ (Reaction (R2)). In addition, we expect that ammonia was released from the ammonium metal sulphates and from ammonium sulphate. In the flash vaporisation process ammonium sulphate is expected to partially decompose into sulphuric acid without prior fragmentation into water and sulphur oxides. All those substances marked with "g" after the vaporisation process could be detected by the AMS. The metal oxides cannot be evaporated on the AMS vaporiser and are thus invisible to the instrument. However, as a major fraction of the sulphuric acid probably reacted with the particle surface and formed metal sulphates, the fragments $\mathrm{HSO}_{3}^{+}$ and $\mathrm{H}_{2} \mathrm{SO}_{4}^{+}$were expected to be lower. The reaction of the sulphuric acid can thus be detected by the relative reduction of these hydrogenated fragments. Ammonium could not be quantified.

The next set of reactions shows the effect of sulphuric acid coating followed by the thermodenuder set to $250^{\circ} \mathrm{C}$ :

$$
\begin{array}{cl}
\stackrel{250^{\circ} \mathrm{C}}{\rightarrow} & \mathrm{M}_{2}\left(\mathrm{CO}_{3}\right)_{3}+\mathrm{H}_{2} \mathrm{SO}_{4} \\
\stackrel{\text { vaporiser }}{\rightarrow} & \mathrm{M}_{2}\left(\mathrm{SO}_{4}\right)_{3}+\mathrm{CO}_{2}(\mathrm{~g})+\mathrm{H}_{2} \mathrm{O}(\mathrm{g}) \\
\mathrm{M}_{2} \mathrm{O}_{3}+\mathrm{SO}_{\mathrm{i}}(\mathrm{g})
\end{array}
$$

Reaction (R3) is similar to Reaction (R1) with respect to the chemical reaction of the sulphuric acid with the particle surface. However, no ammonium is expected to be involved. Without the water bath, the uptake of ammonia is slowed down and only a minor fraction of the sulphuric acid could be neutralised. The main substances which formed on the particle surface were metal sulphates. These decomposed into metal oxides and sulphur oxides on the AMS vaporiser. Since only the sulphur oxides can be detected, the fragments $\mathrm{HSO}_{3}^{+}$and $\mathrm{H}_{2} \mathrm{SO}_{4}^{+}$should again be strongly reduced. Only small amounts of unreacted sulphuric acid and ammonium sulphate might be left on the surface.

The last set of reactions show the effects of processing the ATD by sulphuric acid condensation followed by the water bath and the thermodenuder set to $250{ }^{\circ} \mathrm{C}$ : 


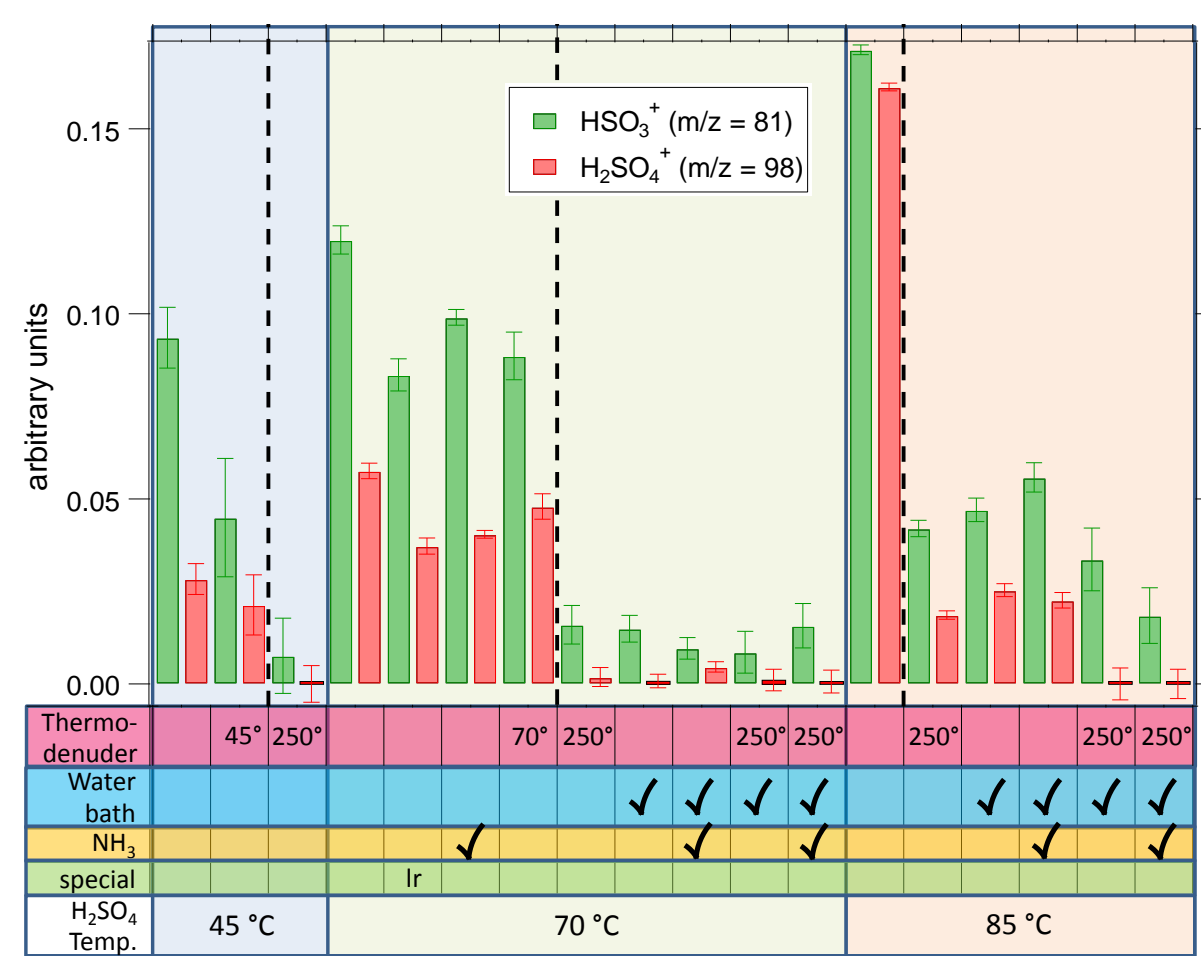

Fig. 7. Intensity of the fragments $\mathrm{HSO}_{3}^{+}(\mathrm{m} / z=81)$ and $\mathrm{H}_{2} \mathrm{SO}_{4}^{+}(\mathrm{m} / z=98)$ normalised to the intensity of the fragment $\mathrm{SO}_{2}^{+}(\mathrm{m} / z=64)$ for the FROST2 campaign. On the horizontal axis, the first line now shows the thermodenuder temperature in contrast to Fig. 1 , the second one indicates if the water bath was used, the third one if ammonium was added. The "lr" marked in the special line refers to an experiment with an additional residence volume of 101 after the particle coating. The last line refers to the temperature of the sulphuric acid coating section.

$$
\begin{array}{ll}
\stackrel{\mathrm{M}_{2}\left(\mathrm{CO}_{3}\right)_{3}+\mathrm{H}_{2} \mathrm{SO}_{4}+\mathrm{NH}_{3}}{\rightarrow} & \mathrm{M}_{2}\left(\mathrm{SO}_{4}\right)_{3}+\mathrm{MNH}_{4}\left(\mathrm{SO}_{4}\right)_{2}+\left(\mathrm{NH}_{4}\right)_{2} \mathrm{SO}_{4} \\
& +\mathrm{CO}_{2}(\mathrm{~g})+\mathrm{H}_{2} \mathrm{O}(\mathrm{g}) \\
\stackrel{250^{\circ} \mathrm{C}}{\rightarrow} & \mathrm{M}_{2}\left(\mathrm{SO}_{4}\right)_{3}+\mathrm{M}\left(\mathrm{HSO}_{4}\right) \mathrm{SO}_{4} \\
& +\mathrm{NH}_{3}(\mathrm{~g})+\mathrm{H}_{2} \mathrm{O}(\mathrm{g})+\mathrm{SO}_{\mathrm{i}}(\mathrm{g}) \\
\stackrel{\text { vaporiser }}{\rightarrow} & \mathrm{M}_{2} \mathrm{O}_{3}+\mathrm{H}_{2} \mathrm{O}(\mathrm{g})+\mathrm{SO}_{\mathrm{i}}(\mathrm{g})
\end{array}
$$

Reaction (R5) is identical to Reaction (R1) and depicts the effect of the water bath. The following reaction (Reaction (R6)) refers to the effect of the thermodenuder on particles which had been humidified beforehand. We expected that no chemical reactions would take place in this processing step. Only parts of the materials formed in Reaction (R5) were decomposed. These were ammonium sulphate and the ammonium metal sulphates. Only metal sulphates and bisulphates were expected to be left after the ATD passed the thermodenuder. On the AMS vaporiser, these compounds decomposed to metal sulphates, water and sulphur oxides. Again the hydrogenated fragments $\mathrm{HSO}_{3}^{+}$and $\mathrm{H}_{2} \mathrm{SO}_{4}^{+}$can only occur from unreacted sulphuric acid or ammonium sulphate. Since the thermodenuder and the water bath were used together, we expected that for these experiments only very few unreacted sulphuric acid and ammonium sulphate are left on the particle surface. Thus the hydrogenated fragments should be lowest for these experiments.

The reaction schemes above showed that both the water bath and the thermodenuder should lead to surface reactions which reduce the hydrogenated fragments of the sulphate species. The fragmentation patterns recorded by the AMS confirm these reaction schemes. Figure 7 shows the hydrogenated fragments for experiments with coated ATD after different treatments. The blue background refers to a sulphuric acid bath temperature of $45^{\circ} \mathrm{C}$, the green and the red background refer to coating temperatures of $70^{\circ} \mathrm{C}$ and $85^{\circ} \mathrm{C}$, respectively. The categories on the right of the dashed line of each coating temperature correspond to measurements for which the water bath and/or the thermodenuder was used at a higher temperature as was used for the coating itself. Comparing the categories on the left side of the dashed line for the different coating temperatures to those categories on the right shows that the use of the thermodenuder and/or the water bath reduced the hydrogenated fragments. This is in accordance with what was expected from the proposed reaction schemes (R1) to (R7). At coating temperatures of $45^{\circ} \mathrm{C}$ and $70^{\circ} \mathrm{C}$, the hydrogenated fragments disappeared nearly completely. However, for particles coated at $85^{\circ} \mathrm{C}$ the hydrogenated fragment ions still have significant intensity. Most likely, the reaction with the particle surface was 


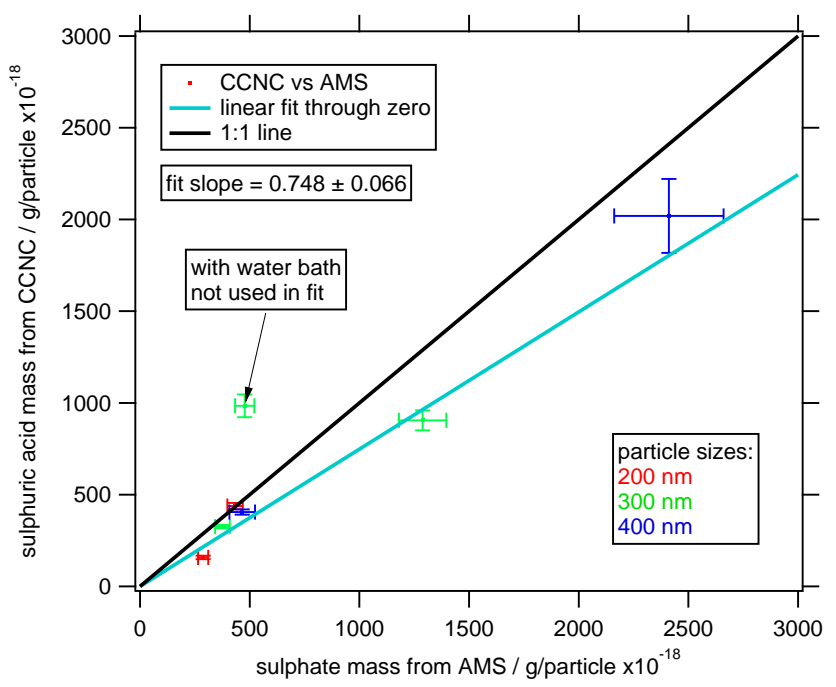

Fig. 8. Comparison of AMS sulphate per particle masses to CCNC soluble mass per particle for the FROST1 campaign. The outlying point was recorded with the water bath in use.

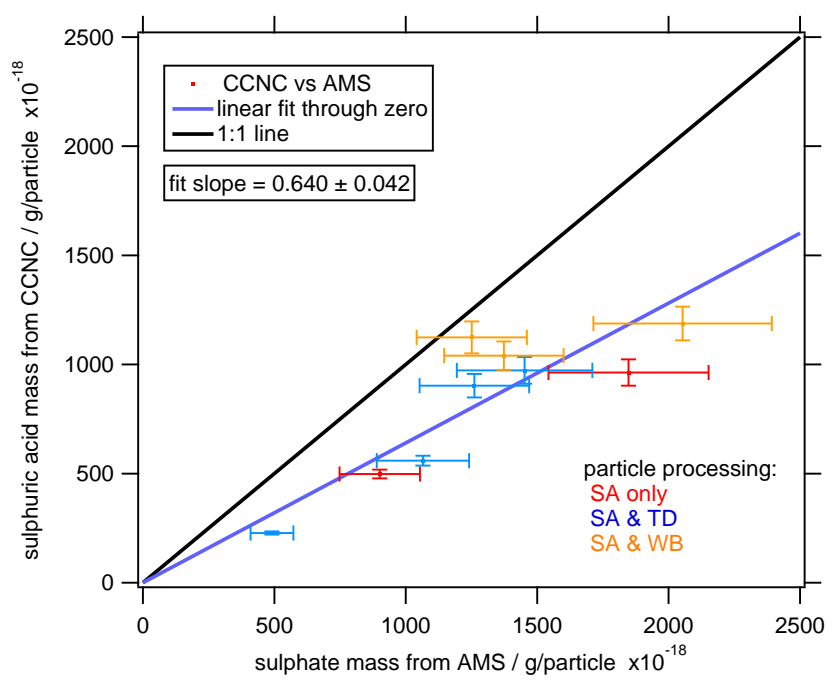

Fig. 9. Comparison of AMS sulphate per particle masses for $300 \mathrm{~nm}$ particles to CCNC soluble mass per particle for the FROST2 campaign. Different treatments were used: SA only refers to sulphuric acid coating only, TD indicates that the thermodenuder was used and $\mathrm{WB}$ refers to the water bath.

not fast enough for these thicker coatings to completely consume the sulphuric acid. Furthermore, the ammonium signal (not shown) indicated that for those particles which were not heated in the thermodenuder, part of the sulphuric acid reacted with ammonia to form ammonium sulphate and was therefore no longer available for reactions with the ATD surface. As expected the fragments $\mathrm{HSO}_{3}^{+}$and $\mathrm{H}_{2} \mathrm{SO}_{4}^{+}$were lowest, when both the TD and the WB were used.

\subsection{Comparison of non refractory mass loadings to soluble mass loadings}

In Fig. 8 the soluble mass per particle, calculated from the CCNC data as described in Sect. 2.2.1, is plotted versus the sulphate mass per particle measured with the AMS. The amount of soluble mass was calculated under the assumption that it was composed of sulphuric acid. This assumption was made for simplification as we do not exactly know which substances have been created on the particle surface by reaction of sulphuric acid with the ATD particles. The graph shows a linear relation between the soluble mass and the non-refractory mass at $600^{\circ} \mathrm{C}$, except for one point. The point marked "with water bath", which is located away from the linear fit, was an experiment with the water bath in use during the FROST1 campaign. It showed no hydrogenated sulphate fragments at all. The reduction of the hydrogen containing fragments indicates that the reaction with the particle surface was accelerated, most likely producing more material which is soluble but cannot be evaporated at $600{ }^{\circ} \mathrm{C}$, as described in Sect. 3.2, and can therefore not be detected by the AMS. This data point indicates a chemical modification of the particle by the use of the water bath but further study of this system is needed to confirm this hypothesis.

Figure 9 shows the comparison of soluble mass to AMS sulphate mass per particle for the FROST2 campaign. As already mentioned, during this campaign, the temperature of the AMS vaporiser was set to $820^{\circ} \mathrm{C}$ which was $220^{\circ} \mathrm{C}$ higher than during FROST1. This allows for the vaporisation of additional substances compared to FROST1. The graph shows that with the higher temperature all experiments show a linear relation between CCNC and AMS.

The slope of the fit curve for both comparison graphs is the same within the error (FROST1: 0.75; FROST2: 0.64) due to the $30 \%$ calibration accuracy of the AMS. This indicates that the material produced by chemical reaction on the particle surface without the water bath could already be completely evaporated at $600^{\circ} \mathrm{C}$, while the material produced with the water bath must have a higher vaporization temperature than the reaction products without water bath. No thermodenuder experiments were performed during FROST1 but a similar effect than with the water bath can be expected for the different denuder temperatures. Substances that were produced without the water bath could be iron(II)- and iron(III) sulphate. Candidates for the additional compounds produced with the water bath are aluminium sulphate and calcium sulphate. As shown in Table 2, all three metals can be found on the ATD surface in relatively high abundance. The iron sulphate salts decompose at $400{ }^{\circ} \mathrm{C}$ and $480{ }^{\circ} \mathrm{C}$ while aluminium sulphate decomposes at $770{ }^{\circ} \mathrm{C}$ and calcium sulphate at $700{ }^{\circ} \mathrm{C}$ (IFA, 2010). It is possible to detect iron sulphate salts in the AMS with a vaporiser temperature of $600^{\circ} \mathrm{C}$ but for aluminium sulphate more than $770^{\circ} \mathrm{C}$ and for calcium sulphate more than $700^{\circ} \mathrm{C}$ are necessary in order to get flash decomposition of these substance. In Table 2 a more 
extensive list of possible reaction products is shown together with their respective decomposition temperatures and their solubility. For some substances the table contains the melting temperature, as this temperature corresponds in good approximation to the evaporation temperature under high vacuum conditions prevailing in the AMS. This list of compounds is of course not complete, as a lot of other reaction products are possible on the ATD surface. The table shows that all compounds except $\mathrm{CaSO}_{4}$ have a solubility higher than $100 \mathrm{gl}^{-1}$ indicating that all of these substances contributed to the apparent hygroscopicity determined with the CCNC (Sullivan et al., 2009b; Petters and Kreidenweis, 2008). Considering the data point with humidification by the water bath in Fig. 8 , we cannot explain its behaviour with the formation of $\mathrm{CaSO}_{4}$ e.g. from $\mathrm{CaCO}_{3}$ as $\mathrm{CaSO}_{4}$ is not soluble enough to be measured with the CCNC (details in Wex et al. (2011).

However this does not exclude that $\mathrm{CaSO}_{4}$ was formed too. The additional formation of $\mathrm{Al}_{2}\left(\mathrm{SO}_{4}\right)_{3}$ from e.g. $\mathrm{AlPO}_{4}$ or alumino silicates could explain this behaviour. From the ATD analysis by Vlasenko et al. (2005) we know that small amounts of phosphate can be found in ATD. Possible precursors of $\mathrm{Al}_{2}\left(\mathrm{SO}_{4}\right)_{3}$ could also be minerals containing $\mathrm{OH}^{-}$ anions. The proposed reactions are all based on the material available. Reliable conclusions on the exact chemistry of the surface reactions need more investigations, especially to directly identify the products of the reactions.

\subsection{Effect of particle surface modification on IN ability}

In this section the number fraction of IN is linked to the results of the AMS data as shown in Figs. 10 and 11. More details about the evaluation and interpretation of the IN data is presented in Sullivan et al. (2010b) (CFDC) and Niedermeier et al. (2010) (LACIS). Both graphs illustrate that the number fraction of IN was reduced with increasing amounts of sulphate per particle. In Fig. 10 the ice fraction was measured with the CFDC at $105 \%$ relative humidity with respect to water and a freezing temperature of $-30^{\circ} \mathrm{C}$. With these parameters, the analysed freezing mode was condensation or immersion freezing, meaning that the particles froze during or shortly after the activation of liquid droplets. The experiments with the water bath in use show a lower fraction of IN than experiments with the same amount of sulphate mass on its surface but without the water bath. In Sect. 3.2 we showed that when the particles were humidified by the water bath, no free, unreacted sulphuric acid was left on the particle surface. The sulphuric acid either reacted with the surface itself or was neutralised by the uptake of ammonia. Therefore it can be concluded that the main reason for the reduction of the IN fraction in the immersion/condensation freezing mode is not the coverage of the particle surface with sulphuric acid, but a chemical modification of the surface.

This hypothesis is supported by the comparison of the AMS mass loadings to the IN fractions calculated from the LACIS data shown in Fig. 11. All the data from LACIS refer

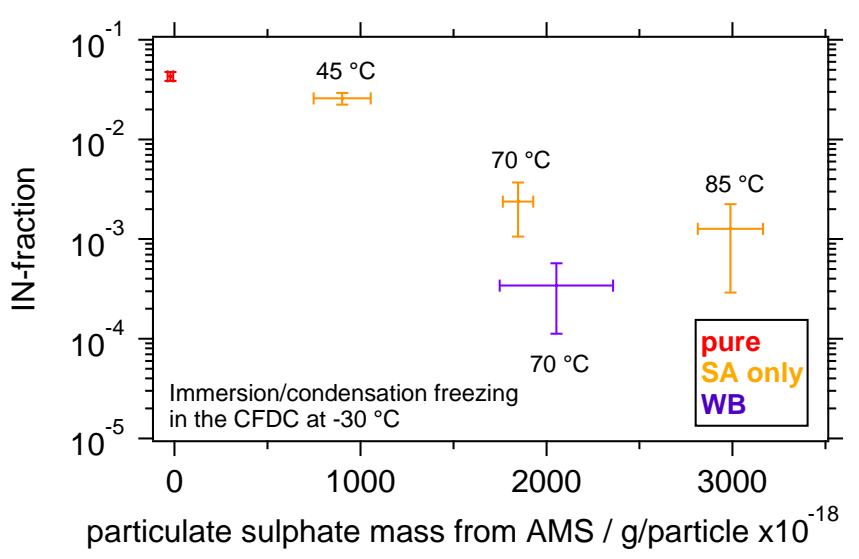

Fig. 10. Comparison of AMS sulphate per particle masses to CFDC ice nucleus counter at $-30{ }^{\circ} \mathrm{C}$ in the immersion-freezing regime (adapted from Sullivan et al., 2010b). Different coating temperatures are shown for the different particle classes. The particle class pure includes those experiments with no treatment and no sulphuric acid condensation. The particles class "SA only" includes particles which passed the sulphuric acid bath but no further processing was performed and WB indicates the use of the water bath. The INactivity of the ATD is reduced if more sulphuric acid is condensed on the particle surface and the use of the water bath decreases the number of IN even further.

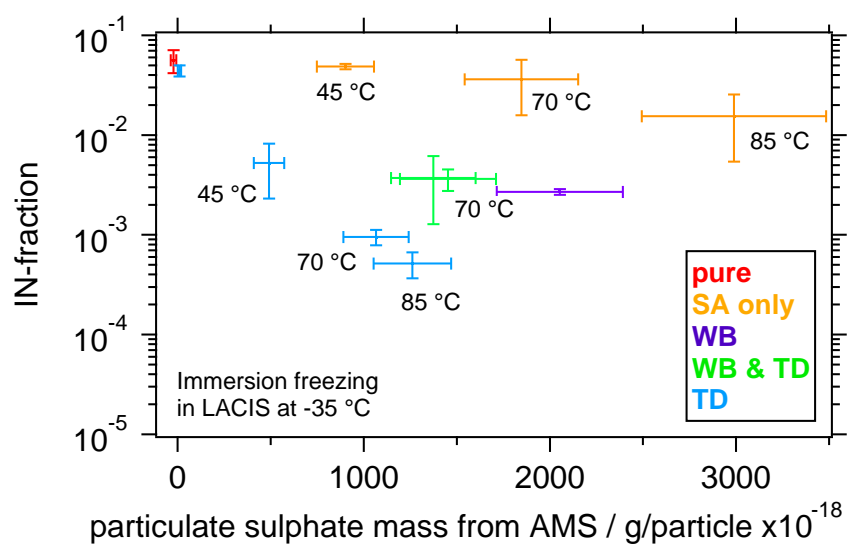

Fig. 11. Comparison of AMS sulphate per particle masses to the LACIS ice nucleus counts at $-35^{\circ} \mathrm{C}$ during FROST2. Different sulphuric acid bath temperatures are shown for every particle class. The particle class pure includes those experiments with no treatment and no sulphuric acid condensation. The particles class "SA only" includes particles which passed the sulphuric acid bath but no further processing was performed. WB indicates the use of the water bath and TD the use of the thermodenuder after the treatment except for the blue point on the upper left which passed the thermodenuder but was not coated.

to immersion freezing. For the particles with no treatment after the condensation of sulphuric acid, the IN fraction was reduced when the amount of sulphate was increasing. If the 
Table 2. ATD surface elemental composition from XPS as found by Vlasenko et al. (2005) and possible compounds formed with these substances. Mg is expected to be on the particle surface as it is found in the bulk material, but the XPS data was recorded with an Mg anticathode, masking the $\mathrm{Mg}$ of the sample. The list shown below is only a proposal for possible reaction products based on the availability of the respective material. We were not able to directly identify these compounds. The numbers in the two last columns indicate the decomposition temperature $T_{\mathrm{d}}$ in ${ }^{\circ} \mathrm{C}$ and the solubility $S_{20}$ at $20^{\circ} \mathrm{C}_{\text {in }} \mathrm{gl}^{-1}$ (IFA, 2010).

\begin{tabular}{ccccc}
\hline element & fraction at ATD surface [\%] & possible compounds & $T_{\mathrm{d}}$ & $S_{20}$ \\
\hline $\mathrm{Na}$ & 2 & $\mathrm{Na}_{2} \mathrm{SO}_{4}$ & 890 & 170 \\
& & $\mathrm{NaHSO}_{4}$ & 315 & 1080 \\
\hline $\mathrm{Mg}$ & - & $\mathrm{MgSO}_{4}$ & 1124 & 300 \\
\hline $\mathrm{Al}$ & 24 & $\mathrm{Al}_{2}\left(\mathrm{SO}_{4}\right)_{3}$ & 770 & 364 \\
& & $\mathrm{AlNH}_{4}\left(\mathrm{SO}_{4}\right)_{2}$ & $190^{1}$ & 150 \\
\hline $\mathrm{Si}$ & 63 & $\mathrm{no} \mathrm{information}$ & - & - \\
\hline $\mathrm{K}$ & 3 & $\mathrm{~K}_{2} \mathrm{SO}_{4}$ & $1069^{1}$ & 111.1 \\
& & $\mathrm{KHSO}_{4}$ & 195 & 490 \\
\hline $\mathrm{Fe}$ & 3 & $\mathrm{Fe}(\mathrm{III}) \mathrm{SO}_{4}$ & 400 & 256 \\
& & $\mathrm{Fe}(\mathrm{III})_{2}\left(\mathrm{SO}_{4}\right)_{3}$ & 480 & 4400 \\
& & $\mathrm{NH}_{4} \mathrm{Fe}(\mathrm{III})\left(\mathrm{SO}_{4}\right)_{2}$ & $41^{1,2}$ & $1240^{3}$ \\
\hline $\mathrm{Ca}$ & 5 & $\mathrm{CaSO}$ & 700 & 2 \\
\hline
\end{tabular}

${ }^{1}$ Melting temperature, ${ }^{2}$ source: AlfaAeser (2010), ${ }^{3}$ source: Sitzmann (2004) at $25^{\circ} \mathrm{C}$.

water bath is used, the IN fraction is reduced by one order of magnitude. This is in accordance with the finding in Sect. 3.2 where we showed that the use of the water bath reduced the intensity of those sulphate fragments that are typical for the presence of sulphuric acid. Using the thermodenuder has a similar but stronger effect. The thermodenuder however not only favours the surface reactions but it also removed part of the semi-volatile material. This has to be taken into account when interpreting those experiments where the thermodenuder was used after the water bath. The thermodenuder has no significant effect on the IN fraction when used after the water bath. It only reduces the sulphate mass on the particle surface to about $70 \%$, moving the points on the graph to the left by a factor of approximately 1.5. As all of the coating material has already reacted with the surface or was neutralised due to the improved ammonia uptake on the wet particles, no sulphuric acid is left which could further attack active sites due to the heat treatment. Niedermeier et al. (2011) cover more details about the behaviour of the IN fraction and show data for different freezing temperatures in the LACIS chamber.

The reduction of the IN-efficiency of ATD through the reaction with sulphuric acid can be explained by the following hypothesis: the nucleation ability of mineral dust to act as ice nuclei is thought to be linked to surface active sites (Vali, 1985) which may provide a structure similar to that of ice (i.e.: cubic or hexagonal ice), thereby lowering the energy barrier for ice formation to be initialised. Experiments performed by Choi et al. (2005) indicate that local electric fields present on the particle surface could also act as active sites. Monte Carlo simulations by Croteau et al. (2010) indicate that trenches in the Kaolinite can order water ferroelectrically. Such ordered water structures could initialise the formation of ice. Similar to ATD, Kaolinite is a mineral composed of alumino silicates and it could therefore potentially be found on the ATD surface. However, this needs further investigation. Different active site properties not stated here are also possible as the nature of active sites is still not identified.

In Sullivan et al. (2010b) we showed that the ATD INefficiency is irreversibly altered by the processing with sulphuric acid. We believe that through reaction with sulphuric acid, active sites were destroyed. Whether this happens via etching of structures that favour the formation of ice or via changing the chemical nature of the surface remains unclear. It is also possible that both effects are involved. This hypothesis implies that the material forming the active sites can react with and/or is etched by sulphuric acid, which reduces the possible compounds or mixtures of compounds responsible for the ATD IN-behaviour. Whether these compounds form structures, e.g. trenches, which lower the energy barrier to form ice or provide a crystal lattice similar to ice could not be accessed by these experiments. The substances additionally formed when the water bath or the thermodenuder was used were likely to contain calcium and aluminium. In future laboratory studies it would therefore be interesting to analyse 
pure aluminium and calcium containing minerals which can be etched by sulphuric acid. As we found that carbonates have been destroyed by the sulphuric acid, it is possible that carbonates are involved in the ice formation as suggested by Klein et al. (2010); Zimmermann et al. (2008); Mason and Maybank (1958), and Manson (1957). The comparison of the AMS non refractory mass at $600{ }^{\circ} \mathrm{C}$ to the soluble mass from the $\mathrm{CCNC}$, indicates that the destruction of aluminium and phosphates or hydroxide containing minerals could also be involved in the chemical processes on the particle surface. Whether the destruction of such substances is linked to the destruction of the IN ability of ATD or not cannot be determined from these experiments and other compounds which we were unable to identify may also be responsible for the observed effect.

The humidification of a particle transforms the sulphuric acid on its surface into a highly concentrated sulphuric acid solution with the particle core immersed. This allows for two possible explanations for the effect of the water bath. First, the sulphuric acid could have been spread over the whole particle and thus became able to etch all active sites on the ATD surface. Thus those active sites could also be affected which were not in contact with the sulphuric acid if the particle surface was not completely covered after the condensation process. A second possibility is that the particles were already completely covered after the condensation of the sulphuric acid and the humidification only accelerated the reaction kinetics and/or changed the reaction equilibrium. When the thermodenuder was applied, the same effects are possible. The second possibility is supported by the following argument: Colina et al. (2002) reported that the alumino silicate kaolin reacts with sulphuric acid when heated. This might as well happen in the case of ATD and could be the reason for the reduction of the ice active fraction. If the thermodenuder only accelerated the reaction kinetics and/or changed the reaction equilibrium without further spreading the sulphuric acid over the particle surface, it is likely that most of the particle surface was covered by sulphuric acid. If the particles were only partially covered, the thermodenuder could not have efficiently altered the IN ability as only the covered fraction of the particle's surface could have been affected. In the situation of particles that were completely covered with sulphuric acid, the effect of the humidification must also have been linked to reaction kinetics and/or reaction equilibrium. However, the first explanation can not be ruled out. If the thermodenuder also favoured the spreading of the sulphuric acid over the particle surface, the effect of both the thermodenuder and the water bath could be an increased surface coverage. Thus the sulphuric acid could have reacted with a higher fraction of the particle surface and could have destroyed more active sites. In both cases, the sulphuric acid reacted with the ATD surface, as the hydrogenated fragments disappeared in the mass spectrum for both the water bath and the thermodenduer treatment (Sect. 3.2). If the particles were not further treated after the condensation of the sulphuric acid, parts of the sulphuric acid remained unreacted on the particle surface. A possible explanantion could be a passivation of the ATD surface after an initial reaction with the sulphuric acid.

\section{Summary and conclusions}

Mineral dust has been recognized as the most relevant IN in the atmosphere (Kamphus et al., 2010; Mertes et al., 2007; Richardson et al., 2007; Cziczo et al., 2004; DeMott et al., 2003). However, it is unlikely that mineral dust is found in its pure, untreated form after a few hours or days of residence time in the atmosphere. Various atmospheric processes will alter the nature of the surface of the dust particles. One of such processing is reaction with sulphuric acid which may be important especially in polluted areas with high sulphure emissions.

We showed that condensing sulphuric acid on the ATD surface does not only coat the particles but also leads to surface reactions. The compounds produced on the surface were metal sulphate salts, ammonium metal sulphate salts as well as ammonium sulphate. The formation of metal sulphate salts was indirectly detected via the fragmentation pattern of the AMS sulphate signal. A direct detection was not possible as the metal oxides produced during the vaporisation process in the AMS are refractory. In our experiments the source of the ammonium was the intrinsic ammonia contained in the compressed air, a possible contamination of the water bath section as well as ammonia that was on purpose added to the system to get full neutralisation.

Comparing the AMS data to the CCNC data for particles humidified or treated thermally after the coating with sulphuric acid yielded evidence for the formation of an increased amount of substances which were evaporated by the AMS vaporiser at $820^{\circ} \mathrm{C}$ but not at the lower temperature of $600^{\circ} \mathrm{C}$. However, the solubility of the surface material is altered only weakly. Possible compounds would be aluminium sulphate and calcium sulphate. The comparison of the AMS sulphate signal and the sulphate fragmentation to the IN fractions measured with the CFDC and LACIS show that the IN ability is reduced by the coating with sulphuric acid through reaction with the surface for the condensation/immersion freezing mode.

Coating the particles with sulphuric acid without further treatment slightly lowered the fraction of IN in the immersion/condensation freezing mode, while humidification after the coating and thermal treatment caused the IN-fraction to further decrease. The reduction of the IN fraction was attributed to the destruction of surface active sites as already proposed by Sullivan et al. (2010b). The condensation of sulphuric acid on the particle surfaces and the resulting reaction decreased the IN ability. The substances formed were vaporised at $600{ }^{\circ} \mathrm{C}$ in the AMS. The use of the water bath further decreased the number fraction of IN and produced substances 
with lower volatility and lower solubility. The newly formed substances could only be evaporated at $820^{\circ} \mathrm{C}$. A similar but stronger effect was produced by the use of the thermodenuder if it was not preceded by the water bath. If the water bath was used before the thermodenuder, the thermodenuder effect was reduced to the removal of the volatile fraction of the particle. Aluminium and calcium containing minerals are likely part of the active sites. We observed that the sulphuric acid reduced the amount of carbonates on the particles, indicating that they could be involved in the active site compounds (Klein et al., 2010; Zimmermann et al., 2008; Mason and Maybank, 1958; Manson, 1957). However further research is needed to clearly identify the chemical nature of the active sites.

The goal of these experiments was to retrieve basic information on the nature of active sites. They were not meant to exactly simulate atmospheric processes. While humidification in the water bath provokes hygroscopic growth, the heat treatment of the thermodenuder does not correspond to a process commonly found in the atmosphere. Our experiments were made only with sulphuric acid, but it is not unlikely that other acids (e.g. nitric acid or organics acids) will have similar effects to the dust surface, but this still has to be verified by future experiments.

\section{Appendix A}

\section{Calculation of AMS correction factors}

\section{A1 Relative ionisation efficiency of sulphate and ammonium}

To get the appropriate values of the RIE of sulphate and ammonium two methods have been applied. For the first method an internally mixed aerosol of ammonium nitrate and ammonium sulphate was generated by atomising a solution with a known ratio of ammonium sulphate and ammonium nitrate. The ammonium and the sulphate relative ionisation efficiencies could then be determined directly from the ratio to the nitrate signal. As the instrument was calibrated to nitrate, the nitrate signal is correct. A second method was to measure pure ammonium nitrate and pure ammonium sulphate. The RIE for ammonium can be determined from the ammonium nitrate measurement allowing for the correction of the ammonium concentration of the second measurement. The corrected ammonium concentration of the ammonium sulphate measurement can be compared to the sulphate signal. The RIE of sulphate is determined via the expected correct stoichiometric ratio.

Table A1 shows the determined relative ionisation efficiencies. The RIEs determined in this study significantly differ from the RIE presented in literature. Alfarra et al. (2004) determined RIE of 3.5 and 1.15 for ammonium and sulphate respectively and Drewnick et al. (2005) found values of 3.78

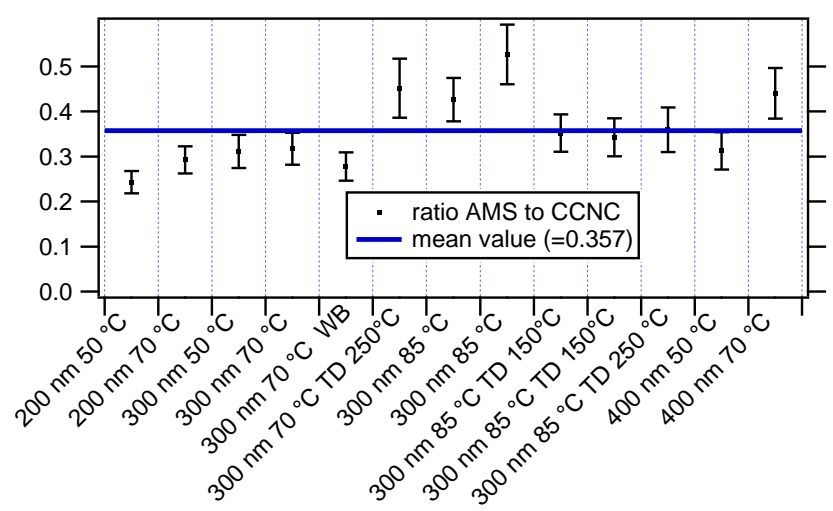

Fig. A1. Collection efficiency (CE) for all experiments using coated BCR particles. The labels of each data point refer to the treatments used in each experiment. The first number is the size of the particles. It is followed by the temperature of the sulphuric acid coating unit. WB indicates the use of the water bath and TD indicates that the thermodenuder was used at the temperature following "TD".

Table A1. Relative ionisation efficiencies (RIE) for the species sulphate and ammonium for the FROST1 and FROST2 campaign.

\begin{tabular}{ccc}
\hline campaign & sulphate & ammonium \\
\hline FROST1 & $0.615 \pm 0.011$ & $4.739 \pm 0.079$ \\
FROST2 & $0.694 \pm 0.024$ & $6.08 \pm 0.13$ \\
\hline
\end{tabular}

and 1.2. The differences are due to the tuning of the ion optics which introduce the ions into the mass spectrometer. The voltages were set in a way that the ions were introduced into the mass spectrometer with different efficiencies depending on their mass to charge ratio. The RIE of the organics is most likely also affected by the tuning. However, as no conclusions were drawn from the organic mass, we did not determine a RIE for organics.

\section{A2 Collection efficiency of ATD-like particles: calibration to the CCNC}

A known issue of the AMS mass quantification is that particles bounce off the vaporiser before they are evaporated (Huffman et al., 2005; Matthew et al., 2008). This effect reduces the collection efficiency (CE) of the AMS. Furthermore, the mass per particle for similar experiments of the FROST1 and the FROST2 campaign was not well reproduced by the AMS. Indeed, there was a difference of a factor of 4 between the FROST1 and the FROST2 campaign. Part of this discrepancy is due to accumulated errors from the AMS calibration accuracy (30\%) and the CPC accuracy $(10 \%)$. In addition the dilution stage, which was used prior to the CPC because of flow limitations, caused an uncertainty of $10 \%$. As the dilution was close to a factor of 5 , the uncertainty of the measurement of the dilution flow was highly 

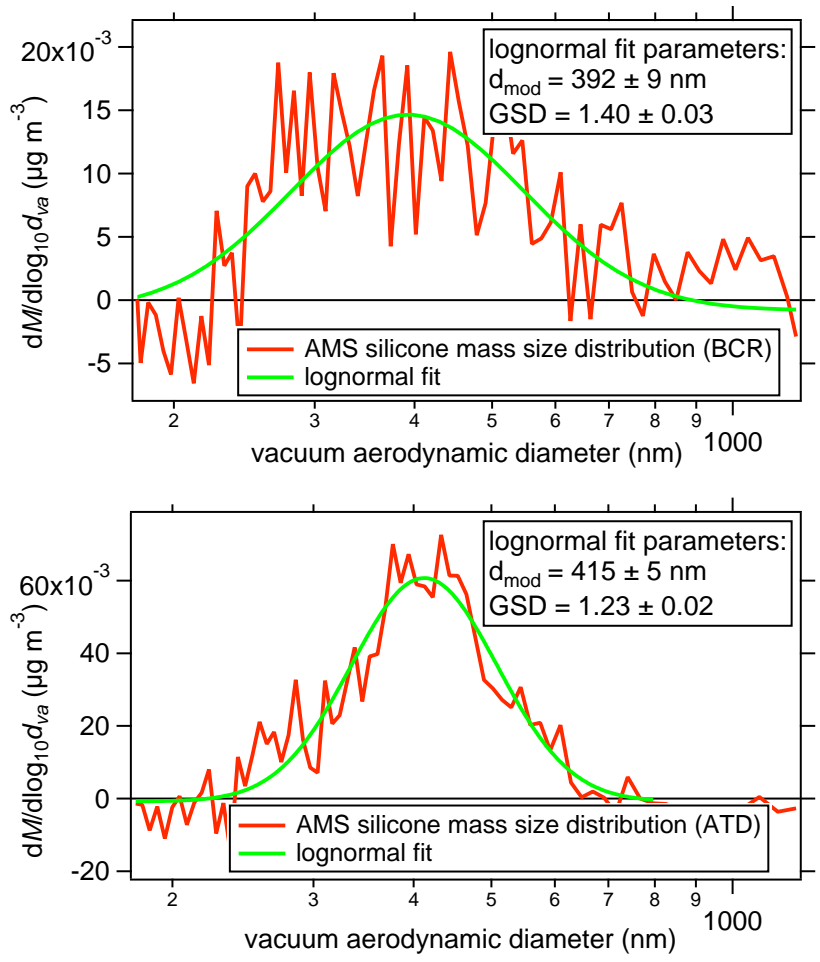

Fig. A2. Silicone size distributions for $200 \mathrm{~nm}$ mobility diameter particles with log normal fit. Upper graph: BCR, averaged over $1 \mathrm{~h}$ and $20 \mathrm{~min}$ lower graph: ATD, averaged over $5 \mathrm{~h}$ and $39 \mathrm{~min}$

amplified. By Gaussian error propagation, these uncertainties add up to $33 \%$ for one standard deviation. In the less likely but posssible case of an error of two standard deviations, the error could be $66 \%$. Nevertheless, these considerations cannot explain the complete discrepancies. We therefore expect that an additional source for errors was present. A possible candidate would be a misalignment of the aerodynamic lens. A misalignment could have happened during the set-up of the instrument, altering the CE for ATD. During the campaign, the alignment was stable as the experiments could be reproduced during every campaign.

The CCNC reproduced the mass per particle for similar aerosol generation settings for which the AMS-CPC-dilution unit showed high differences. Thus, to overcome these high uncertainties, the AMS-CPC-dilution-unit-system was calibrated to the CCNC for the determination of the mass per particle. We used monodisperse quartz particles (BCR-66, European commission, Institute for Reference Materials and Measurements) coated with sulphuric acid for this calibration as ATD would not be suitable. It was necessary to use a material dust which does not chemically react with the sulphuric acid and which is insoluble. Furthermore, the material must be refractory at $600{ }^{\circ} \mathrm{C}$ and it should be similar to ATD with respect to the bounce off behaviour. Of the commercially available particles, BCR- 66 fulfilled these prerequisites best. In an extra campaign, the coated BCR-66 particles were sam- pled in parallel by the CCNC and the AMS together with the CPC. During this extra campaign the CPC was operated without dilution stage. The soluble material per particle was determined by the CCNC as described in Sect. 2.2.1 and the non-refractory mass per particle was determined by the AMS together with the CPC. As the AMS and the CCNC can only detect the sulphuric acid on the particles, the mass per particle could be compared to calibrate the AMS. For the calibration campaign, the effective collection efficiency of the AMS-CPC unit was determined to $0.36 \pm 0.02$. The data is presented in Fig. A1.

To apply this calibration to the FROST1 and the FROST2 campaign, experiments of both campaigns have been repeated during the calibration campaign. The CCNC confirmed that the mass per particle loadings were reproduced. The mass per particle determined with the AMS and the CPC were compared between the calibration campaign and the FROST campaign. The effective CE during the FROST campaign was $0.78 \pm 0.06$ and for the FROST2 campaign it was $0.16 \pm 0.02$. The real CE is not accessible, but with the calibration of the AMS-CPC-dilution-stage unit to the CCNC, it was possible to determine the correct mass per particle for both campaigns.

\section{A3 Aerodynamic lens transmission}

The aerodynamic lens of the AMS has a transmission of $100 \%$ for aerodynamic diameters of up to $600 \mathrm{~nm}$. Above this size, the transmission is slowly decreasing. The particles most extensively characterised in our studies had a mobility diameter of $300 \mathrm{~nm}$, corresponding to a vacuum aerodynamic diameter of about $600 \mathrm{~nm}$. This is at the $100 \%$ transmisson edge of the aerodynamic lens. Due to an aerodynamic shape factor variability of the ATD particles, the monodisperse aerosol with respect to its mobility diameter is polydisperse with respect to its vacuum aerodynamic diameter. This causes a fraction of the particles to be outside of the $100 \%$ transmission range of the aerodynamic lens. For the $400 \mathrm{~nm}$ particles this effect is even more pronounced. In order to get accurate mass loadings, this extra loss factor was estimated. Because the low amounts of non-refractory material on the particles produced noisy size distributions and the size calibration above $600 \mathrm{~nm}$ is imprecise, the following assumptions were made: the vacuum aerodynamic mass size distribution of the ATD was assumed to be lognormally distributed with the same geometric width independent of the mode diameter (Fig. A2). The lognormal fit to the $200 \mathrm{~nm}$ particles which are fully within the $100 \%$ transmission range of the aerodynamic lens, can be projected to the 300 and $400 \mathrm{~nm}$ particles. For that we take advantage that the vacuum aerodynamic diameter $d_{\mathrm{va}}$ and the mobility diameter $d_{\mathrm{mob}}$ are linearly linked by the "Jayne shape factor" $S$ and the particle density $\rho_{\mathrm{p}}$ (Eq. (A1), (DeCarlo et al., 2004; Jayne et al., 2000)). $S$ was determined to be approximately 0.77 and the 

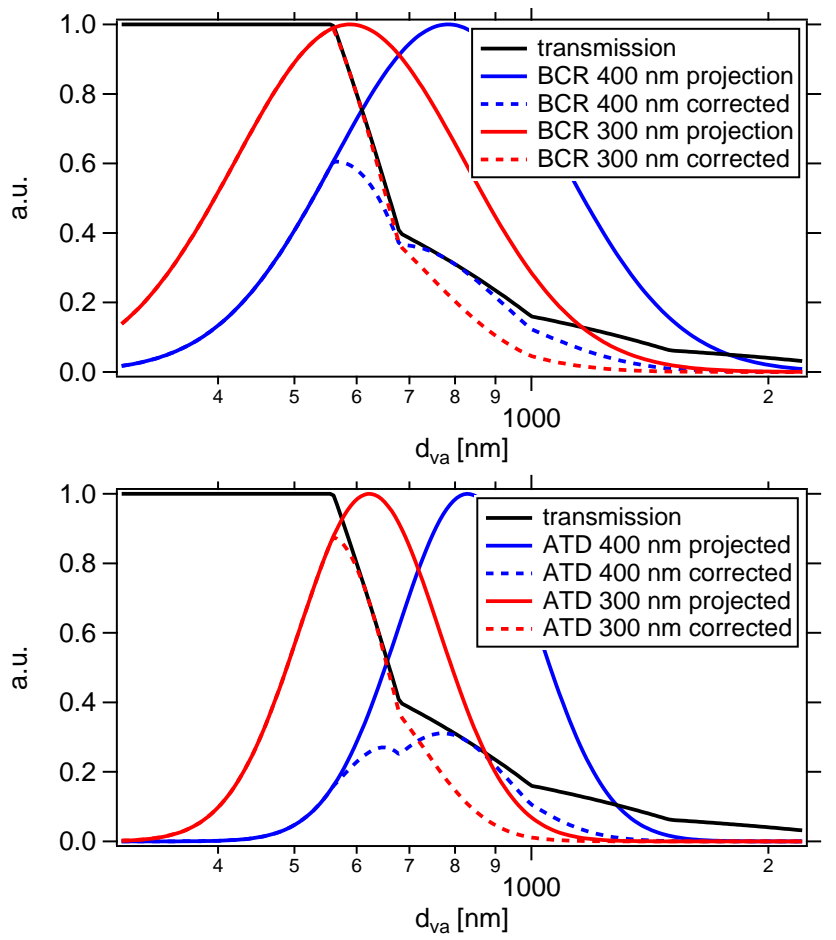

Fig. A3. Transmission correction for BCR and ATD particles. The figures show the projected transmission curves as calculated from the fits in Fig. A2 as well as the projected size distribution when the transmission of the aerodynamic lens is taken into account.

density of the ATD is $2.6 \mathrm{gcm}^{-3}$ (Möhler et al., 2008). $\rho_{0}$ is the unit density $\left(1 \mathrm{gcm}^{-3}\right)$.

$d_{\mathrm{va}}=S \frac{\rho_{\mathrm{p}}}{\rho_{0}} d_{\mathrm{mob}}$

The mass size distributions were calculated from the methyl silicone signal, as this substance showed the best signal to noise ratio. The presence of this substance on the particle surface is discussed in more detail in Sect. 3.1. A second assumption was that the transmission function $f_{\text {trans }}$ of the aerodynamic lens for ATD and BCR-66 particles is identical to that of polystyrol latex size standards (PSL). These were used to determine the transmission function during laboratory measurements (Walter, 2008). Finally the integral of the projected mass size distribution $D_{\text {ATD }}$ was divided by the integral of the product of the transmission function and the projected mass size distribution. This results in a correction factor $k_{\text {trans }}$ for the lens transmission (Eq. A2). The respective projected distributions are shown in Fig. A3. The correction factors are shown in Table A2.

$k_{\text {trans }}=\frac{\int_{0}^{+\infty} D_{\mathrm{ATD}}\left(d_{\mathrm{va}}\right) d d_{\mathrm{va}}}{\int_{0}^{+\infty} D_{\mathrm{ATD}}\left(d_{\mathrm{va}}\right) \times f_{\text {trans }}\left(d_{\mathrm{va}}\right) d d_{\mathrm{va}}}$
Table A2. Transmission correction factors: The errors have been estimated by varying the mode diameter and the geometric width in the range of the fitting parameter uncertainties.

\begin{tabular}{cc}
\hline particle type & correction factor \\
\hline BCR $300 \mathrm{~nm}$ & $1.45 \pm 0.08$ \\
BCR $400 \mathrm{~nm}$ & $2.31 \pm 0.20$ \\
ATD $300 \mathrm{~nm}$ & $1.50 \pm 0.041$ \\
ATD $400 \mathrm{~nm}$ & $3.0 \pm 0.21$ \\
\hline
\end{tabular}

Acknowledgements. This work was conducted within the Helmholtz virtual institute on aerosol cloud interaction and supported by the Integration of European Simulation Chambers for Investigating Atmospheric Processes (EUROCHAMP) program as well as by the US National Science Foundation (Grant ATM0611936). We thank all the participants of the FROST campaigns for their support and valuable discussions.

The service charges for this open access publication have been covered by the Max Planck Society.

Edited by: D. Knopf

\section{References}

AlfaAeser: data sheet ammonium iron(III) sulphate, 2010.

Alfarra, M. R., Coe, H., Allan, J. D., Bower, K. N., Boudries, H., Canagaratna, M. R., Jimenez, J. L., Jayne, J. T., Garforth, A. A., Li, S. M., and Worsnop, D. R.: Characterization of urban and rural organic particulate in the lower Fraser valley using two aerodyne aerosol mass spectrometers, Atmos. Environ., 38, 57455758, doi:10.1016/j.atmosenv.2004.01.054, 2004.

Allan, J. D., Delia, A. E., Coe, H., Bower, K. N., Alfarra, M. R., Jimenez, J. L., Middlebrook, A. M., Drewnick, F., Onasch, T. B., Canagaratna, M. R., Jayne, J. T., and Worsnop, D. R.: A generalised method for the extraction of chemically resolved mass spectra from aerodyne aerosol mass spectrometer data, J. Aerosol Sci., 35, 909-922, doi:10.1016/j.jaerosci.2004.02.007, 2004.

Cantrell, W. and Heymsfield, A.: Production of ice in tropospheric clouds - A review, B. Am. Meteorol. Soc., 86, 795, doi:10.1175/bams-86-6-795, 2005.

Choi, E. M., Yoon, Y. H., Lee, S., and Kang, H.: Freezing transition of interfacial water at room temperature under electric fields, Phys. Rev. Lett., 95, 085701, doi:10.1103/PhysRevLett.95.085701, 2005.

Colina, F. G., Esplugas, S., and Costa, J.: High-Temperature Reaction of Kaolin with Sulfuric Acid, Ind. Eng. Chem. Res., 41, 4168-4173, doi:10.1021/ie010886v, 2002.

Croteau, T., Bertram, A. K., and Patey, G. N.: Observations of High-Density Ferroelectric Ordered Water in Kaolinite Trenches using Monte Carlo Simulations, J. Phys. Chem. A, 114, 83968405, doi:10.1021/jp104643p, 2010.

Cziczo, D. J., Murphy, D. M., Hudson, P. K., and Thomson, D. S.: Single particle measurements of the chemical composition of cirrus ice residue during CRYSTAL-FACE, J. Geophys. Res.Atmos., 109(13), D04201, doi:10.1029/2003jd004032, 2004. 
DeCarlo, P. F., Slowik, J. G., Worsnop, D. R., Davidovits, P., and Jimenez, J. L.: Particle morphology and density characterization by combined mobility and aerodynamic diameter measurements. Part 1: Theory, Aerosol Sci. Tech., 38, 1185-1205, doi:10.1080/027868290903907, 2004.

DeMott, P. J., Sassen, K., Poellot, M. R., Baumgardner, D., Rogers, D. C., Brooks, S. D., Prenni, A. J., and Kreidenweis, S. M.: African dust aerosols as atmospheric ice nuclei, Geophys. Res. Lett., 30, 4, 1732, doi:10.1029/2003gl017410, 2003.

Drewnick, F., Hings, S. S., DeCarlo, P., Jayne, J. T., Gonin, M., Fuhrer, K., Weimer, S., Jimenez, J. L., Demerjian, K. L., Borrmann, S., and Worsnop, D. R.: A new time-of-flight aerosol mass spectrometer (TOF-AMS) - Instrument description and first field deployment, Aerosol Sci. Tech., 39, 637-658, doi:10.1080/02786820500182040, 2005.

Drewnick, F., Hings, S. S., Alfarra, M. R., Prevot, A. S. H., and Borrmann, S.: Aerosol quantification with the Aerodyne Aerosol Mass Spectrometer: detection limits and ionizer background effects, Atmos. Meas. Tech., 2, 33-46, doi:10.5194/amt-2-332009, 2009.

Falkovich, A. H., Ganor, E., Levin, Z., Formenti, P., and Rudich, Y.: Chemical and mineralogical analysis of individual mineral dust particles, J. Geophys. Res., 106, 18029-18036, doi:10.1029/2000jd900430, 2001.

Forster, P., Ramaswamy, V., Artaxo, P., Berntsen, T., Betts, R., Fahey, D., Haywood, J., Lean, J., Lowe, D., Myhre, G., Nganga, J., Prinn, R., Raga, G., Schulz, M., and Van Dorland, R.: Changes in Atmospheric Constituents and in Radiative Forcing, in: Climate Change 2007: The Physical Science Basis. Contribution of Working Group I to the Fourth Assessment Report of the Intergovernmental Panel on Climate Change, edited by: Solomon, S., Qin, D., Manning, M., Chen, Z., Marquis, M., Averyt, K. B., Tignor, M., Miller, H. L., Cambridge University Press, Cambridge, United Kingdom and New York, NY, USA, Cambridge, 2007.

Gallavardin, S. J., Froyd, K. D., Lohmann, U., Möhler, O., Murphy, D. M., and Cziczo, D. J.: Single Particle Laser Mass Spectrometry Applied to Differential Ice Nucleation Experiments at the AIDA Chamber, Aerosol Sci. Technol., 42, 773-791, doi:10.1080/02786820802339538, 2008.

Hartmann, S., Niedermeier, D., Voigtländer, J., Clauss, T., Shaw, R. A., Wex, H., Kiselev, A., and Stratmann, F.: Homogeneous and heterogeneous ice nucleation at LACIS: operating principle and theoretical studies, Atmos. Chem. Phys., 11, 1753-1767, doi:10.5194/acp-11-1753-2011, 2011.

Hinz, K. P., Trimborn, A., Weingartner, E., Henning, S., Baltensperger, U., and Spengler, B.: Aerosol single particle composition at the Jungfraujoch, J. Aerosol Sci., 36, 123-145, doi:10.1016/j.jaerosci.2004.08.001, 2005.

Huffman, J. A., Jayne, J. T., Drewnick, F., Aiken, A. C., Onasch, T., Worsnop, D. R., and Jimenez, J. L.: Design, modeling, optimization, and experimental tests of a particle beam width probe for the aerodyne aerosol mass spectrometer, Aerosol Sci. Technol., 39, 1143-1163, doi:10.1080/02786820500423782, 2005.

IFA: GESTIS-material-database,, http://www.dguv.de/ifa/de/gestis/ stoffdb/index.jsp, last access: January 2011, 2010.

Jayne, J. T., Leard, D. C., Zhang, X. F., Davidovits, P., Smith, K. A., Kolb, C. E., and Worsnop, D. R.: Development of an aerosol mass spectrometer for size and composition analysis of submicron particles, Aerosol Sci. Technol., 33, 49-70, 2000.
Kamphus, M., Ettner-Mahl, M., Klimach, T., Drewnick, F., Keller, L., Cziczo, D. J., Mertes, S., Borrmann, S., and Curtius, J.: Chemical composition of ambient aerosol, ice residues and cloud droplet residues in mixed-phase clouds: single particle analysis during the Cloud and Aerosol Characterization Experiment (CLACE 6), Atmos. Chem. Phys., 10, 8077-8095, doi:10.5194/acp-10-8077-2010, 2010.

Kay, J. E., Baker, M., and Hegg, D.: Physical controls on orographic cirrus inhomogeneity, Atmos. Chem. Phys., 7, 37713781, doi:10.5194/acp-7-3771-2007, 2007.

Klein, H., Nickovic, S., Haunold, W., Bundke, U., Nillius, B., Ebert, M., Weinbruch, S., Schuetz, L., Levin, Z., Barrie, L. A., and Bingemer, H.: Saharan dust and ice nuclei over Central Europe, Atmos. Chem. Phys., 10, 10211-10221, doi:10.5194/acp10-10211-2010, 2010.

Liu, P. S. K., Deng, R., Smith, K. A., Williams, L. R., Jayne, J. T., Canagaratna, M. R., Moore, K., Onasch, T. B., Worsnop, D. R., and Deshler, T.: Transmission efficiency of an aerodynamic focusing lens system: Comparison of model calculations and laboratory measurements for the Aerodyne Aerosol Mass Spectrometer, Aerosol Sci. Technol., 41, 721-733, doi:10.1080/02786820701422278, 2007.

Lohmann, U. and Feichter, J.: Global indirect aerosol effects: a review, Atmos. Chem. Phys., 5, 715-737, doi:10.5194/acp-5-7152005, 2005.

Manson, J. E.: Calcium carbonate as an ice nucleus, J. Meteorol., 14, 85-86, 1957.

Mason, B. J. and Maybank, J.: Ice-nucleating properties of some natural mineral dusts, Q. J. Roy. Meteorol. Soc., 84, 235-241, 1958.

Matthew, B. M., Middlebrook, A. M., and Onasch, T. B.: Collection efficiencies in an Aerodyne Aerosol Mass Spectrometer as a function of particle phase for laboratory generated aerosols, Aerosol Sci. Technol., 42, 884-898, doi:10.1080/02786820802356797, 2008.

Mertes, S., Verheggen, B., Walter, S., Connolly, P., Ebert, M., Schneider, J., Bower, K. N., Cozic, J., Weinbruch, S., Baltensperger, U., and Weingartner, E.: Counterflow virtual impactor based collection of small ice particles in mixed-phase clouds for the physico-chemical characterization of tropospheric ice nuclei : Sampler description and first case study, Aerosol Sci. Technol., 41, 848-864, doi:10.1080/02786820701501881, 2007.

Möhler, O., Buttner, S., Linke, C., Schnaiter, M., Saathoff, H., Stetzer, O., Wagner, R., Krämer, M., Mangold, A., Ebert, V., and Schurath, U.: Effect of sulfuric acid coating on heterogeneous ice nucleation by soot aerosol particles, J. Geophys. Res.-Atmos., 110(12), D11210, doi:10.1029/2004jd005169, 2005.

Möhler, O., Benz, S., Saathoff, H., Schnaiter, M., Wagner, R., Schneider, J., Walter, S., Ebert, V., and Wagner, S.: The effect of organic coating on the heterogeneous ice nucleation efficiency of mineral dust aerosols, Environ. Res. Lett., 3(8), 025007, doi:10.1088/1748-9326/3/2/025007, 2008.

Niedermeier, D., Hartmann, S., Shaw, R. A., Covert, D., Mentel, T. F., Schneider, J., Poulain, L., Reitz, P., Spindler, C., Clauss, T., Kiselev, A., Hallbauer, E., Wex, H., Mildenberger, K., and Stratmann, F.: Heterogeneous freezing of droplets with immersed mineral dust particles - measurements and parameterization, Atmos. Chem. Phys., 10, 3601-3614, doi:10.5194/acp-10-36012010, 2010. 
Niedermeier, D., Hartmann, S., Clauss, T., Wex, H., Kiselev, A., Sullivan, R. C., DeMott, P. J., Petters, M. D., Reitz, P., Schneider, J., Mikhailov, E., Sierau, B., Stetzer, O., Reimann, B., Bundke, U., Shaw, R. A., Buchholz, A., Mentel, T. F., and Stratmann, F.: Experimental study of the role of physicochemical surface processing on the IN ability of mineral dust particles, Atmos. Chem. Phys. Discuss., 11, 18557-18588, doi:10.5194/acpd-1118557-2011, 2011

Nordmeyer, T. and Prather, K. A.: Real-time measurement capabilities using aerosol time-of-flight mass-spectrometry, Anal. Chem., 66, 3540-3542, 1994.

Petters, M. D. and Kreidenweis, S. M.: A single parameter representation of hygroscopic growth and cloud condensation nucleus activity, Atmos. Chem. Phys., 7, 1961-1971, doi:10.5194/acp-71961-2007, 2007.

Petters, M. D. and Kreidenweis, S. M.: A single parameter representation of hygroscopic growth and cloud condensation nucleus activity - Part 2: Including solubility, Atmos. Chem. Phys., 8, 6273-6279, doi:10.5194/acp-8-6273-2008, 2008.

Pruppacher, H. and Klett, J.: Microphysics of clouds and precipitation, pp. 296-360, Kluwer Academic Publishers, Netherlands, 2nd Edn., 1997.

Reitz, P. and Schneider, J.: Noise level determination by local cubic signal approximation: Calculation of Aerodyne Aerosol Mass Spectrometer Detection Limits, Atmos. Meas. Tech. Discuss., in preparation, 2011.

Richardson, M. S., DeMott, P. J., Kreidenweis, S. M., Cziczo, D. J., Dunlea, E. J., Jimenez, J. L., Thomson, D. S., Ashbaugh, L. L., Borys, R. D., Westphal, D. L., Casuccio, G. S., and Lersch, T. L.: Measurements of heterogeneous ice nuclei in the western United States in springtime and their relation to aerosol characteristics, Journal of Geophysical Research-Atmospheres, 112(16), D02209, doi:10.1029/2006jd007500, 2007.

Roberts, G. C. and Nenes, A.: A continuous-flow streamwise thermal-gradient $\mathrm{CCN}$ chamber for atmospheric measurements, Aerosol Sci. Tech., 39, 206-221, 2005.

Roedel, W.: Physik unserer Umwelt: die Atmosphäre, SpringerVerlag Berlin Heidelberg New York, 3rd Edn., 2000.

Rogers, D. C., DeMott, P. J., Kreidenweis, S. M., and Chen, Y.: A Continuous-Flow Diffusion Chamber for airborne measurements of ice nuclei, J. Atmos. Ocean. Tech., 18, 725-741, doi:10.1175/1520-0426(2001)018;0725:ACFDCF 2 2.0.CO;2, 2001.

Sitzmann, H.: Roempp Online - Version 3.5, http://www.roempp. com, last access: January 2011, 2004.

Stratmann, F., Kiselev, A., Wurzler, S., Wendisch, M., Heintzenberg, J., Charlson, R. J., Diehl, K., Wex, H., and Schmidt, S.: Laboratory studies and numerical simulations of cloud droplet formation under realistic supersaturation conditions, J. Atmos. Ocean. Tech., 21, 876-887, 2004.

Sullivan, R. C. and Prather, K. A.: Investigations of the diurnal cycle and mixing state of oxalic acid in individual particles in Asian aerosol outflow, Environ. Sci. Technol., 41, 8062-8069, doi:10.1021/es071134g, 2007.

Sullivan, R. C., Guazzotti, S. A., Sodeman, D. A., and Prather, K. A.: Direct observations of the atmospheric processing of Asian mineral dust, Atmos. Chem. Phys., 7, 1213-1236, doi:10.5194/acp-7-1213-2007, 2007.

Sullivan, R. C., Moore, M. J. K., Petters, M. D., Kreidenweis, S. M.,
Roberts, G. C., and Prather, K. A.: Timescale for hygroscopic conversion of calcite mineral particles through heterogeneous reaction with nitric acid, Phys. Chem. Chem. Phys., 11, 78267837, 2009a.

Sullivan, R. C., Moore, M. J. K., Petters, M. D., Kreidenweis, S. M., Roberts, G. C., and Prather, K. A.: Effect of chemical mixing state on the hygroscopicity and cloud nucleation properties of calcium mineral dust particles, Atmos. Chem. Phys., 9, 33033316, doi:10.5194/acp-9-3303-2009, 2009b.

Sullivan, R. C., Miñambres, L., DeMott, P. J., Prenni, A. J., Carrico, C. M., Levin, E. J. T., and Kreidenweis, S. M.: Chemical processing does not always impair heterogeneous ice nucleation of mineral dust particles, Geophys. Res. Lett., 37, L24805, doi:10.1029/2010gl045540, 2010a.

Sullivan, R. C., Petters, M. D., DeMott, P. J., Kreidenweis, S. M., Wex, H., Niedermeier, D., Hartmann, S., Clauss, T., Stratmann, F., Reitz, P., Schneider, J., and Sierau, B.: Irreversible loss of ice nucleation active sites in mineral dust particles caused by sulphuric acid condensation, Atmos. Chem. Phys., 10, 1147111487, doi:10.5194/acp-10-11471-2010, 2010b.

Svane, M., Hagstrom, M., and Pettersson, J. B. C.: Chemical analysis of individual alkali-containing aerosol particles: Design and performance of a surface ionization particle beam mass spectrometer, Aerosol Sci. Technol., 38, 655-663, doi:10.1080/02786820490485944, 2004.

Svane, M., Hagstrom, M., and Pettersson, J. B. C.: Online measurements of individual alkali-containing particles formed in biomass and coal combustion: Demonstration of an instrument based on surface ionization technique, Energ. Fuel., 19, 411-417, doi:10.1021/ef049925g, 2005.

Vali, G.: Atmospheric Ice Nucleation - A Review, Journal de Recherches Atmospheriques, 19, 105-115, 1985.

Vlasenko, A., Sjogren, S., Weingartner, E., Gaggeler, H. W., and Ammann, M.: Generation of submicron Arizona test dust aerosol: Chemical and hygroscopic properties, Aerosol Sci. Technol., 39, 452-460, doi:10.1080/027868290959870, 2005.

Walter, S.: Personal communication: AMS lens transmission function, 2008.

Wex, H., Hennig, T., Salma, I., Ocskay, R., Kiselev, A., Henning, S., Massling, A., Wiedensohler, A., and Stratmann, F.: Hygroscopic growth and measured and modeled critical supersaturations of an atmospheric HULIS sample, Geophys. Res. Lett., 34(5), L02818, doi:10.1029/2006g1028260, 2007.

Wex, H., Clauss, T., Covert, D., Hallbauer, E., Hartmann, S., Kiselev, A., Mentel, T. F., Mildenberger, K., Niedermeier, D., Poulain, L., Reitz, P., Schneider, J., Shaw, R., Spindler, C., and Stratmann, F.: Classifying Coated and Uncoated Arizona Test Dust with respect to Hygroscopic Growth and Activation, in preparation, 2011.

Wiacek, A. and Peter, T.: On the availability of uncoated mineral dust ice nuclei in cold cloud regions, Geophys. Res. Lett., 36(5), L17801, doi:10.1029/2009g1039429, 2009.

Zhao, D. F., Buchholz, A., Mentel, Th. F., Mller, K.-P., Borchardt, J., Kiendler-Scharr, A., Spindler, C., Tillmann, R., Trimborn, A., Zhu, T., and Wahner, A.: Novel method of generation of $\mathrm{Ca}\left(\mathrm{HCO}_{3}\right)_{2}$ and $\mathrm{CaCO}_{3}$ aerosols and first determination of hygroscopic and cloud condensation nuclei activation properties, Atmos. Chem. Phys., 10, 8601-8616, doi:10.5194/acp-10-86012010, 2010. 
Zimmermann, F., Weinbruch, S., Schütz, L., Hofmann, H., Ebert, M., Kandler, K., and Worringen, A.: Ice nucleation properties of the most abundant mineral dust phases, J. Geophys. Res., 113, D23204, doi:10.1029/2008jd010655, 2008. 